\title{
Financial Market Contagion during the Global Financial Crisis
}

\author{
Sabur Mollah ${ }^{\mathrm{i}}$ \\ Goran Zafirovii \\ AMM Shahiduzzaman Quoreshiii
}

\begin{abstract}
Scholars worldwide have provided both theoretical and empirical insights into financial market contagion. The devastation from the recent financial crisis is immeasurable, and researchers commonly believe that the crisis seemingly originated from the U.S. and spread immediately to the other global financial hubs. Several studies have been conducted on financial markets, but this issue has yet to be addressed. Using U.S. dollar-denominated MSCI daily indices for the period 2006-2010, this paper employs Dynamic Conditional CorrelationGeneralized Autoregressive Conditional Heteroskedasticity (DCC-GARCH) and vector error correction (VEC) models to address the multi-dimensional phenomena around financial market contagion. The empirical results demonstrate the existence of contagion in the financial markets during the global crisis. However, the crisis originated in the U.S., and its effects escalated immediately to the other global markets. The results also indicate that benefits from portfolio diversification decayed significantly among countries during the crisis.
\end{abstract}

Keywords: Contagion, Financial Markets, Global Crisis

JEL Classification: F36, G01, C58

\section{Introduction}

The bankruptcy of Lehman Brothers was the world's first alarm about the imminent financial crisis that primarily began to take shape in the U.S. and was suspected to have inevitably spread throughout the world. The Lehman bankruptcy was followed by the takeover of Merrill Lynch by Bank of America and the consequent rescue of AIG. HBOS plc, Britain's largest mortgage lender, was taken over by Lloyds TSB, followed by the nationalization of the European banking and insurance giant Fortis and the rescue plan in 
Germany. In 2008, the tsunami-like crisis began to spread rapidly across the globe and immediately became a worldwide issue. Many countries had large budget deficits and significant national and international debt. In addition, a number of emerging market economies, such as Hungary, Ukraine, Latvia and Iceland, suffered from severe financial crises and sought emergency assistance from the International Monetary Fund (IMF). The situation in Greece was worse. Experts throughout the world agreed that the world was approaching the deepest recession since World War II. In short, large financial institutions either collapsed or were purchased, and even governments in the world's wealthiest nations had to develop rescue packages to bail out their financial systems during the crisis. ${ }^{\text {iv }}$

The realization that a crisis would ensue, which became evident in world markets and the Dow Jones, peaked in May 2008, and the ensuing months revealed the possibility of a crisis spreading from the housing market to the entire economy. The events of September 2008 are usually synonymous with the global financial crisis. Lehman Brothers filed for bankruptcy on September 15, and Bank of America announced the purchase of Merrill Lynch on the same day. On September 7, the U.S. government used its funds to help struggling Freddie Mac and Fannie Mae and bailed out AIG on September 16. These events, which gained momentum in September, were thereafter reflected in the markets. The Dow Jones lost $6 \%$ in value during the month of September. By the end of October, compared with its value on September 1, it had lost nearly $20 \%$ of its value and lost nearly $25 \%$ of its value by the end of 2008. ${ }^{\mathrm{V}}$ The index continued to decline until March 2009, when it rebounded to regain a significant portion of its losses.

Similar patterns were witnessed around the world. The U.K. FTSE 100 index declined by approximately $25 \%$ by mid-October 2008 and almost $30 \%$ by the end of 2008 , compared with its value on September 1, 2008. As an example from the emerging markets, the BVSPA index in Brazil declined by $35 \%$ by mid-October 2008 and by nearly half of its value by the end of October 2008, after which point it started to recover. These examples show that the crisis hit other countries as well, thus raising the question of how the crisis spread. How many countries suffered because of the crisis that started in the U.S.? In fact, researchers across the world largely believe that the global financial crisis originated in the U.S. from its sub-prime mortgage crisis, whose severity was further intensified through a major breakdown in the financial system that spread rapidly throughout the world. Agreeing with scholars who stated that financial market contagion occurred during the crisis is therefore logical.

Without a doubt, financial market contagion is an issue of enormous interest in the finance literature. Dornbusch et al. (2000) and Pritsker (2001) adopt the definition of contagion as the 
dissemination of market disturbances, primarily with negative consequences, from one market to another. Researchers ${ }^{\mathrm{vi}}$ strongly assert that an excessive increase in the correlation among the countries causing the crisis and all other countries is synonymous with the presence of contagion. We have adopted this definition of contagion in our paper. Bekaert et al. (2005) also identify contagion in equity markets as the notion that markets move more closely together during periods of crisis. Sachs et al. (1996) describe financial market contagion as a significant increase in cross-country correlations of stock market returns and volatility. Understanding whether financial market contagion occurred during the recent financial crisis is a fascinating study.

In contrast, the literature on stock market co-integration suggests that the benefits from portfolio diversification diminish across countries when financial markets move more closely together. In this regard, Arshanapalli and Doukas (1993), McInish and Lau (1993), and Meric and Meric (1997) demonstrate that global portfolio diversification benefits to investors decrease significantly when the correlation between national stock markets increases. Hon, Strauss, and Yong (2006) also suggest that the benefits of international diversification in times of crisis are substantially diminished.

This research adopted multi-approach econometric techniques to answer the research question(s). First of all, Engle and Sheppard's (2001) model is employed to determine the nature of correlation ${ }^{\mathrm{vii}}$ between the country indices. Secondly, the Dynamic Conditional Correlation-Generalized Autoregressive Conditional Heteroskedasticity (DCC-GARCH) model is applied to capture the dynamic nature of the correlation between markets in the U.S. and those of the rest of the world. Thirdly, principal component analysis (PCA) has been conducted to analyze the contagion at the regional level. Fourthly, the vector error correction model (VECM) approach is implemented within the Johansen framework to test Granger causality and the impulse response function (IRF).

The empirical results demonstrate the existence of contagion in financial markets during the global crisis. The results also suggest that the crisis originated in the U.S. and the effects escalated to the other global markets. Principal regional common factors strengthen the country-level results and are evident of the occurrence of contagion in the global financial markets during the crisis. Finally, the co-integration analysis stresses that portfolio diversification benefits decay significantly between countries during the crisis.

The rest of the paper is designed as follows. Section 2 summarizes the existing literature on the issue. Section 3 elaborates on the methodology used in the study. A 
description of the data is provided in section 4. Section 5 presents the empirical evidence, and the concluding remarks are provided in section 6.

\section{Literature Review}

The results from the relatively extensive empirical literature on contagion in equity markets are divergent. Contagion in equity markets refers to the notion that markets move more closely together during periods of crisis (Bekaert et al. 2005). Hon et al. (2006) find that major global events such as a crisis can lead to a change in the cross-country correlation of assets. Ang and Bekaert (2001) and Longin and Solnik (2001) show that cross-correlations of international equity markets are higher during periods of volatility, which is true for major events such as financial crises.

Cappiello et al. (2006) also conclude that, during periods of financial turmoil, equity market volatilities show important linkages and conditional equity correlations among regional groups increase dramatically. Baig and Goldfajn (1998) investigate the contagion effect from the Asian currency crisis on Thailand, Malaysia, Indonesia, South Korea and the Philippines. They consider the presence of contagion between equity and currency markets. Baig and Goldfajn (2000) examine whether there was contagion during the Russian crisis with regard to Brazil and conclude that contagion occurred and that the mechanism of propagation was the debt securities market. They also note the sudden halt in capital flows to Brazil and Russia. Corsetti et al. (2005) test the contagion effect between Hong Kong, the ten emerging nations and the G7 countries and their evidence suggests that at least five of the seventeen countries showed symptoms of contagion.

In line with Rigobon (2003), Caporale et al. (2003) also conclude that there was evidence of contagion during the Asian crisis. At the same time, Billio et al. (2003) observe that the Asian crisis was unable to handle contagion testing given the inadequate testing procedure. Longin and Solnik (2001) identify that correlations increased during crises but not during periods of tranquility. Bae et al. (2003) note a few points about their findings: contagion was more serious in Latin America than in Asia; contagion from Latin America to other regions was more important than that in Asia; the United States was not contaminated by the Asian crisis; and contagion is predictable and subject to prior information. Boschi (2005) analyzes contagion effects between Argentina and Brazil, Venezuela, Uruguay, Mexico and Russia but is unable to provide evidence of contagion. However, Collins and 
Gavron (2005) study 44 events of contagion in 42 countries and find that the Brazilian and Argentinean crisis generated most of the contagion events.

Chiang et al. (2007) investigate financial contagion during the Asian crisis. Their results reveal the contagion effect in Asian markets, and they have identified two phases (contagion and herding behavior of correlation) of correlation amongst Asian markets. Sovereign credit rating agencies have played a vital role in shaping the structure of dynamic correlation in the Asian markets. Sola et al. (2002) also test the contagion effects during the emerging market currency crises and have found evidence of contagion from the South Korean crisis to Thailand but not to Brazil. Hon et al. (2006) test whether the terrorist attacks on the U.S. on September 11, 2001 resulted in contagion in financial market. Their results indicate that international stock markets, particularly in Europe, responded closely to the U.S. stock market shocks during the three to six months after the crisis. Alper and Yilmaz (2004) present an empirical analysis of real stock return volatility contagion on the Istanbul Stock Exchange (ISE) from emerging markets. They produce evidence of a volatility contagion from financial centers, particularly on the aftermath of the Asian crisis to the ISE. Khalid and Kawai (2003) investigate the inter-linkages among different markets and countries within the Asian region but do not find any evidence to strongly support contagion.

Kawai and Khalid (2001) analyze the financial market contagion across regions during the "Tequila Crisis," the "Asian Crisis" and the "Russian Crisis." In addition to Asia, they particularly consider the effect of the collapse of the Thai baht on financial markets in Latin America and Europe. Ferna'ndez-Izquierdo and Lafuente (2004) examine the dynamic linkages between international stock market volatility during the Asian crisis in 12 relevant stock exchanges. They focus on the contagion hypothesis around the world and their empirical results tend to support the contagion hypothesis, i.e., significant leverage effects are the result of negative shocks within the market itself and foreign negative shocks.

Bekaert et al. (2005) produce no evidence that the Mexican crisis caused contagion. However, they find economically meaningful increases in residual correlations, particularly in Asia, during the Asian crisis. Dungey and Martin (2001), using a different methodology, find similar results for Asia and explore the role of currency risk in equity market contagion. Nevertheless, in a different type of study, Kaminsky and Schmukler (1999) analyze the type of news that moved markets on market jitter days during the Asian crisis. Their study reveals that movements were triggered by local and neighboring countries and that news about agreements with international organizations and credit rating agencies have the most weight. 
Using correlation analysis, Lee and Kim (1993) find evidence of contagion in the global stock markets after the 1987 U.S. stock market crash. Longstaff (2010) presents strong recent evidence of contagion in the financial markets. His results support the hypothesis that financial contagion was propagated primarily through liquidity and risk-premium channels rather than through a correlated information channel.

Khalid and Rajaguru (2006) note that linkages and/or interdependence amongst financial markets increase because of a financial crisis. Forbes and Rigobon (2002) analyze the contagion effect on the equity markets of emerging and developed countries during the Asian and Mexican crises and the 1987 crash of the New York Stock Exchange. However, they conclude that most of the changes were the result of interdependence. Rigobon (2003) tests contagion during Mexican, Asian and Russian crises. For the Mexican crisis, the mechanism for the transmission of crises remained relatively constant, providing evidence of interdependence. At the same time, evidence of a structural breakdown existed for the Russian crisis and particularly for the Asian crisis.

Many studies consider the recent global financial crisis. Some tackle the specific issue of market contagion, such as Guo et al. (2011) and Longstaff (2010), who study the crossasset contagion between several asset classes in the U.S. market. They find contagion, but because they only tackle cross-asset contagion, they cannot make any conclusions on contagion between the world's markets at the global level. Kenourgios et al. (2011) and Johansson (2011) address contagion between markets, but they have a smaller sample and focus only on either a specific region or a handful of markets. Thus, they are unable to truly gauge contagion on a global level. Another issue with Johansson (2011) is that the study uses the period from 2004 to 2008, which ends when the global financial markets enter the highest level of turmoil. All of these studies find evidence of contagion. Similarly, Bartram and Bodner (2009) study patterns within industry and groupings within several country (for example, developed and emerging). However, because their paper does not directly study correlations, it does not provide answers to the question of contagion.

Chudik and Fratzscher (2011) study twenty-six economies (defining the Euro area as a single economy and excluding China) using weekly data and find that the tightening of financial conditions was the key transmission channel in advanced economies, whereas the real side of the economy was the main channel in emerging economies. Another conclusion of their paper is that Europe suffered a greater effect than other advanced economies from the decline in risk appetite. 
Furthermore, Samarakoon (2011) uses the widest sample of previously detailed studies, including sixty-three emerging and frontier markets (developed markets are excluded in his study). In line with our study, this study starts with an AR(3) model and moves to a VAR framework (whereas we move to a DCC). However, the conclusion of the paper is counterintuitive because it does not find that contagion spread from the U.S. to emerging markets (except for Latin America) but finds that contagion spread from emerging markets to the U.S. market. Nonetheless, Coudert et al. (2011) study the exchange market contagion between emerging markets and find that contagion spread from one to other neighboring emerging countries' foreign exchange markets during a global crisis.

The empirical results are inconclusive. One group of researchers define contagion as a significant increase in cross-country correlations during a crisis; however, the other group claims that, after adjusting for heteroskedasticity, there is no significant increase in crosscountry correlation, which is interdependence. The issue of heteroskedasticity is very important in the empirical research on contagion. Therefore, employment of a multivariate GARCH model such as DCC can help address the issues of heteroskedasticity, or the dynamic nature of correlation.

\section{Testing Procedure}

In this paper, we have employed the AR model class to capture contagion in the world market during the recent global financial crisis. We consider the U.S. as the source of the contagion. As previously discussed, contagion increases in cross-country correlations of stock market returns and volatility. To capture contagion, we have employed a suitable model for capturing cross-country correlations, which can be static or dynamic. Employing the wrong approach may lead to biased results. Hence, we need to test whether the correlations are static or dynamic in nature. Testing the model for constant correlation has proven to be difficult because testing for dynamic correlation using data with time-varying volatilities may result in a misleading conclusion (Engle and Sheppard, 2001) and rejection of a true constant correlation because of mis-specified volatility models. On the one hand, Tse (1998) has conducted a null constant conditional correlation (CCC) against an autoregressive conditional heteroskedasticity (ARCH) in correlation alternative. On the other hand, Bera (1996) has tested a null CCC against a diffuse alternative. Engle and Sheppard (2001) stress that both alternatives failed to generalize the vector at a higher order, which has been identified as a limitation in the testing procedure of a null $\mathrm{CCC}$ against a dynamic alternative; therefore, they suggested testing a null CCC against a DCC within a vector autoregressive framework. 
Following Engle and Sheppard (2001), we propose testing a null CCC against a DCC alternative in a higher order vector autoregressive (VAR) to satisfy the condition that the specific return series and U.S. returns experience a dynamic correlation. We propose a seemingly uncorrelated regression between individual series; U.S. returns have a null $\mathrm{H}_{0}$ : $\alpha=1-\beta$ against the DCC alternative. Under the null, the constant and all of the lagged parameters in the model should be zero.

If the primary conditions of a DCC are satisfied through the estimations, we proceed to apply the DCC framework to identify the presence of contagion at the country level and augment this model with asymmetric influences, as shown by Cappiello et al. (2006). Otherwise, we employ the CCC alternative. For each country $i$ at time $t$, we employ the following models to test the null CCC against the dynamic alternative:

$$
r_{i, t}=\alpha_{0}+\beta_{i} r_{i, t-1}+\beta_{2} r_{t-1}^{u s}+\varepsilon_{i, t}
$$

where, $r_{i, t 1}$ is the country-specific lag return, $r_{t-1}^{U S}$ is the U.S. market return at time $t-l$ and $\left.\varepsilon_{i, t}\right|^{\mathfrak{J}_{t-1}} \approx \mathrm{N}\left(0, \mathrm{H}_{\mathrm{t}}\right)$.

Following Engle (2002) and Cappiello et al. (2006), we estimate the DCC-GARCH using the following equations:

$$
\begin{aligned}
& r_{i, t} \mid \mathfrak{I}_{t-1} \approx \mathrm{N}\left(0, \mathrm{D}_{\mathrm{t}} \mathrm{R}_{\mathrm{t}} \mathrm{D}_{\mathrm{t}}\right) \\
& D_{t}=\operatorname{diag}\left\{\sqrt{h_{i, t}}\right\} \\
& Q_{t}=(1-a-b) \bar{R}+a \varepsilon_{t-1} \varepsilon_{t-1}^{\prime}+b Q_{t-1} \\
& R_{t}=Q_{t}^{*-1} Q_{t} Q_{t}^{*-1}
\end{aligned}
$$

where $D_{t}=\operatorname{diag}\left\{\sqrt{h_{i, t}}\right\}$ is an nxn diagonal matrix with the square roots of the conditional variances in the diagonal, $h_{i, t}$ is obtained by a $\operatorname{GARCH}(1,1), \varepsilon_{i t}=r_{i t} / \sqrt{h_{i t}}$ is the standardized residual ${ }^{1}, r_{i t}$ is the return of series $i$ at time $t$ and $\bar{R}=E\left[\varepsilon_{t} \varepsilon_{t}^{\prime}\right] ; Q_{t}^{*}=\left[q_{i i t}^{*}\right]=$ $\left[\sqrt{q_{i i t}}\right]$. We obtain the $a$ and $b$ by maximizing the log-likelihood of the DCC process given by the following equation:

$$
L=-\frac{1}{2} \sum_{t=1}^{T}\left(n \log (2 \pi)+2 \log \left|D_{t}\right|+\log \left|R_{t}\right|+\varepsilon^{\prime}{ }_{t} R_{t}^{-1} \varepsilon_{t}+r_{t}^{\prime} D_{t}^{-1} D_{t}^{-1} r_{t}^{\prime}-\varepsilon_{t}^{\prime} \varepsilon_{t}\right)
$$

An imposed restriction on the model is that $a+b<1$. We obtain the pattern of dynamic correlations by using equation 5 , for which the dynamic correlation between series $i$ and $j$ at time $t$ is simply equal to $R_{i j t}$. 
If the primary conditions of a DCC are satisfied through the estimations previously mentioned, we proceed to apply the DCC framework to identify the presence of contagion at the country level and augment this model with asymmetric influences as shown by Cappiello et al. (2006) ${ }^{\text {viii }}$. We employ an AR(p) model on the dynamic correlations that we obtained using eq. (1) to test the contagion of the U.S. market onto the different markets in the world. We employ

$$
\hat{\rho}_{i U S t}=\gamma_{0}+\gamma_{1} \hat{\rho}_{i U S t-1}+\delta C r i s i s_{t}+v_{t}
$$

where $\hat{\rho}_{i, U S, t}$ is the DCC between market $i$ and the U.S. market at time t, Crisis $t_{t}$ is a dummy variable for the crisis period and $v_{t}$ is the error term. The presence of contagion is identified with the significant positive coefficient of $\delta$.

We also apply a similar methodology to analyze contagion at the regional level. Following the methodology of Yiu et al. (2010), we first use the principal component technique of Jolliffe (2002) to identify regional factor(s). Subsequently, we perform the following VAR filter for the regional factor(s):

$$
\left[\begin{array}{l}
R F_{t} \\
U S_{t} \\
R L_{t}
\end{array}\right]=\left[\begin{array}{l}
\mu_{R F} \\
\mu_{U S} \\
\mu_{R L}
\end{array}\right]+\sum_{j=1}^{p} A_{j}\left[\begin{array}{l}
R F_{t-j} \\
U S_{t-j} \\
R L_{t-j}
\end{array}\right]+\left[\begin{array}{l}
\varepsilon_{R F, t} \\
\varepsilon_{U S, t} \\
\varepsilon_{R L, t}
\end{array}\right]
$$

We repeat the same methodology for the regional factors that we used for the country indices (eq. 7). We adopted the methodologies of Yiu et al. (2010), Engle (2002), Cappiello et al. (2006) and Jolliffe (2002) and implemented the following model:

$$
\hat{\rho}_{i R P C t}=\gamma_{0}+\gamma_{1} \hat{\rho}_{i R P C t-1}+\delta C \text { risis }{ }_{t}+v_{t}
$$

where $\hat{\rho}_{i R P C, t}$ is the DCC between market $i$ and the regional principal component at time t, Crisis $_{t}$ is a dummy variable for the crisis period and $v_{t}$ is the error term. The presence of contagion is identified with the significant positive coefficient of $\delta$.

To reconfirm whether the U.S. triggered the contagion, we employ a cointegration method. First, we employ the Johansen procedure to determine whether the series are co- 
integrated (Johansen, 1991). Second, we estimate the vector error correction (VEC) model to determine Granger causality (Engle and Granger 1987). Third, we employ an impulse response method to determine the country that triggered the contagion. These methods ${ }^{\mathrm{ix}}$ are also used to determine the effect of portfolio diversification.

\section{Data}

In this paper, we have used daily data ${ }^{\mathrm{x}}$ from January 2006 to December 31, 2010 to study the presence of market contagion during the recent global financial crisis. September $2008^{\mathrm{xi}}$ is believed to be the beginning of the global financial crisis. Thus, we have used the period from September $1,2008^{\text {xii }}$ to December 31,2009 as the actual crisis period for this paper. ${ }^{\text {xiii }}$ This research is dedicated to determining the contagion effect among financial markets and crosscountry cointegration during the global financial crisis.

All of the data have been obtained from DataStream, and we attempted to extract homogenous indices. For all countries, we have used the U.S. dollar-denominated daily MSCI indices instead of indices denominated in local currency to diminish the effects of exchange rate fluctuations. After screening for missing values and inconsistencies, sixty-four indices were obtained.

Table 1 presents a summary of the descriptive statistics of the MSCI indices. The mean returns of the MSCI indices are negligibly different from 0 , and the volatilities are approximately $2 \%$. However, we have observed that the average daily returns are negative for 13 indices. Skewness for most indices appear as 0 or very close to 0 . These findings can help characterize the crisis as a low-return regime. However, we have observed excess kurtosis in each of the 64 indices, indicating that the return series are not normally distributed. The null hypothesis of normality is also rejected through the Jarque-Bera test at a very high level of significance for all indices. Similarly, the ARCH-LM test rejects the null hypothesis of no $\mathrm{ARCH}$ in the series of indices. Thus, we conclude that conditional heteroskedasticity is present in the data. In addition, the results of unit root tests using ADF, PP and KPSS have rejected the null hypothesis of the unit root for all markets, indicating that the return series are trend stationary.

\section{[Insert Table 1 about here]}




\section{Results}

The estimates for equation (1) are presented in Table 2 and show that the AR term in the mean equations are highly significant with a few exceptions but that the coefficients of the U.S. lagged returns are highly significant ${ }^{\mathrm{xiv}}$. These results support a study by Dungey et al. (2003), who found that the effect of U.S. returns on global stock returns is highly significant. The results from Table 2 clearly indicate that individual markets are driven by the global factor "the US return." The AR(1) terms in the mean equation are significantly positive for most emerging markets that indicate price friction or partial adjustment; however, these terms for developed countries are significantly negative, indicating the presence of positive feedback trading in developed countries (e.g., Antoniou et al. 2005).

\section{[Insert Table 2 about here]}

We run seemingly uncorrelated regressions (SUR) between individual series and U.S. returns within the higher order VAR framework to test a CCC against a DCC under the Engle and Sheppard (2001) proposition. The test results are rejected at the 5\% level, indicating that the MSCI return series have a DCC with U.S. returns (Table 3). These results interpret the timevarying volatility characteristics of the return series; that is, the persistence of shocks to volatility depends on $\alpha+\beta$. Engle and Bollerslev (1986), Chou (1988), and Bollerslev et al. (1992) show that if $\alpha+\beta<1$, the tendency is for the volatility response to decay over time. If $\alpha+\beta=1$, volatility persists indefinitely given shocks over time, and if $\alpha+\beta>1$, the persistence of increasing volatility over time/covariance stationary is violated. Although time-varying volatility is evident in the results, most developed countries experience long, persisting shocks. Unfortunately, long-term persistent shocks ( $\beta$ coefficient) are zero for a few countries in the sample, which requires special attention.

\section{[Insert Table 3 about here]}

Figure 1 presents the DCC between the U.S. and the rest of the countries. This graph shows that the correlation increases significantly between the U.S. and other countries from September 2008 to December 2009. This finding shows that an excessive increase in correlation among the countries that caused the crisis and all other countries is synonymous with the presence of contagion (e.g., Masson and Mussa, 1995; Calvo and Reinhart, 1996; 
Sachs et al. 1996; Masson, 1998 and 1999; Forbes and Rigobon, 2002; Pesaran and Pick, 2003; Pritsker, 2001; Pericoli and Sbracia, 2001; and Corsetti et al. 2003).

\section{[Insert Figure 1 about here]}

Next, we turn to the DCC analysis of contagion. As previously described, we have first obtained the residuals from the return equation (eq. 1), which are then used to calculate the dynamic correlation patterns. Finally, these patterns are tested for a dominant contagion effect during a crisis using an $\mathrm{AR}(1)$ model (eq. 7) with a crisis dummy. The results of the $\mathrm{AR}(1)$ model are shown in Table 4. An interesting feature of the model is the significance of the coefficient $\delta$, which implies that the crisis has significantly increased the integration between market $i$ and the U.S. market. Table 4 shows that the coefficients are significantly positive at a high level, with few exceptions. The coefficients of the crisis dummy variable are highly significant in 46 countries. The significance of the dummy variable shows that market contagion has occurred during the recent global financial crisis. The $\mathrm{R}^{2}$ for the AR(1) models of the dynamic correlations for countries in different regions are good $^{\mathrm{xv}}$. Furthermore, for robustness, we run eq. 7 using the three-month interbank interest rates from the global crisis period; however, the crisis is not significant in either case. These results confirm that the contagion does not spread from other channels ${ }^{\mathrm{xvi}}$.

\section{[Insert Table 4 about here]}

We have also used principal component analysis method to detect the contagion effect of the U.S. factor on the regional common factor. The results are reported in Table 5, which shows the principal component eigenvalues and proportion of variance explained by the methodology and each ranked eigenvector. In all regions, the first principal component explains a larger portion of the variance than the subsequent principal components. For this reason, in all further calculations, we have used only the highest ranked principal component that we term the "regional factor." After obtaining the regional factors, we have performed a test by applying a model similar to equation 1 and saved the residuals, which are then used in the DCC methodology. Figure 1 shows the pattern of dynamic correlations obtained between each regional factor and the U.S. and indicates that, for each regional factor, the dynamic correlation is near 0.5 during the crisis. Both the South and the North American regional factor indicate a jump in the dynamic correlation with the U.S. This jump is confirmed in 
Table 5, which shows coefficients of the AR model on the dynamic correlations (eq. 9). All of the regions show highly significant changes in dynamic correlations with the U.S. These results make clear that regional common factors play a key role in spreading the contagion from the U.S. to the global markets during the crisis. Nevertheless, Figure 2 also validates contagion during the financial crisis because the dynamic correlations between the regional common factor and the U.S. are highly significant at this time.

\section{[Insert Table 5 about here]}

\section{[Insert Figure 2 about here]}

Furthermore, we have implemented a VAR framework for contagion testing in the financial markets. First of all, the ADF, PP, and KPSS tests confirm the non-stationarity of level indices for all regional countries. The Johansen procedure is also based on two test statistics, i.e., the maximum eigenvalue and the trace statistic, suggesting that the data follow the VECM approach ${ }^{\mathrm{xii}}$. Granger causality is conducted under the VECM procedure to investigate the bi-directional linkage of the regional countries. The results for the bi-directional linkage between regional countries are presented in Table 7.

\section{[Insert Table 7 about here]}

The bi-directional linkages indicate a significant influence of the U.S. on the rest of the world's countries (Table 7). However, we graphically confirmed these results by investigating the response to Cholesky's one standard deviation innovations of the U.S. to other countries through the impulse response function within a VECM framework. Impulse responses trace the reactions of the dependent variable to a unit shock of all other variables in a dynamic system: by hitting the error term with a shock, one can trace the effects on the dependent variable over time (Brooks 2008). The impulse response between regional countries is presented in Figure 3. All of these figures reflect the global markets' immediate response with one standard deviation shock of the U.S., except for Sweden ${ }^{\text {xviii }}$. These results confirm the significant unidirectional causal linkages, and they confirm that contagion spreads from the U.S. to the rest of the countries throughout the world.

[Insert Figure 3 about here] 
Finally, we conclude that the financial market contagion has occurred during the global financial crisis. During this crisis, the contagion originated from the U.S. and spread rapidly to the rest of the countries around the world. The regional principal component appears as a key factor for some regions. Nonetheless, the co-integration results confirm the high degree of inter-linkages among the financial markets during the crisis, indicating that portfolio diversification benefits decay between countries during a crisis.

\section{Conclusion}

Researchers commonly believe that the crisis seemingly originated from the U.S. and spread to the rest of the global financial hubs in no time. Using U.S. dollar-denominated MSCI daily indices for the period 2006-2010, this paper attempts to investigate whether market contagion occurs during a global crisis. Multiple approach econometric techniques show that contagion occurred during the global financial crisis but that it was not present in all of the world markets. The DCC methodology shows the presence of contagion in forty-six of sixty-three countries. These countries have shown significantly increased correlation with the U.S. market during the financial crisis compared with the period before the crisis. The DCC approach, together with the PCA framework, indicated the presence of contagion at the regional level for all regions in our study, thus confirming that the financial crisis was truly global. However, the Granger causality tests and the Impulse response functions within the VECM framework also confirm these results, except for Sweden. Sweden implemented a similar resolution to address the global crisis that succeeded; therefore, the country was not hit by the global crisis. Nevertheless, diversification benefits significantly decayed between the countries during the crisis.

With respect to studies on the recent global financial crisis, our contribution is threefold. First, we have used a wider sample than other studies and, thus, are able to better judge the scope of contagion during the global financial crisis. We also have used daily data when other studies used weekly or monthly data. Our results confirm that the contagion effect is more prominent in the financial markets when daily data are used instead of weekly data. Samarakoon (2011) tests the contagion effect on the emerging and frontier markets, but we have tested global data. However, other studies have focused only on a single region or group of countries and are incomplete. In contrast, this study has presented a complete picture in this context because it has captured a wide range of markets, including developed, emerging, and frontier markets. Furthermore, the robustness checks using three-month interbank interest rates confirm that contagion spreads through financial markets during a global crisis and not 
through the banking channel. Second, we have tested market contagion using multi-approach econometric techniques (e.g., DCC-GARCH, PCA and VECM), whereas the existing studies on market contagion have adopted a single method. Furthermore, the results of a cointegration analysis within the VECM framework are evidence that portfolio diversification benefits decay between countries during a crisis. These results are new with respect to crisis data. Third, this study has provided an extensive review of the existing studies on market contagion during major financial crises witnessed in the past three decades.

\section{Acknowledgments:}

We acknowledge the financial support from the NASDAQ OMX Nordic Foundation. We benefitted from Eva Liljeblom's comments on the previous draft. We thank Lamia Bekkour for discussing the paper at the FMA International European meeting, June 6-8, 2012, in Istanbul, Mark Schelton for his valuable comments at the BAFA meeting, April 17-19, 2012, in Brighton, and the discussant and participants at the $61^{\text {st }}$ Midwest Finance Association 2012 Meeting, February 22-25, 2012, in New Orleans. We are thankful to Sami Vahama and other participants at the Southern Finance Association 2011 Meeting, November 17-19, in Key West, Vassiliki Papaikonomou for her useful comments at the NFF conference, August 2224, 2011, in Stockholm, and the participants at the $3^{\text {rd }}$ International Conference on Prediction and Information Markets, April 3-5, 2011, in Nottingham, UK. We are also grateful to Gustaf Sporong, Tomas Pangaro, and Alovaddin Kalonov for research assistance.

\section{References}

Acharya, V., Philippon, T., Richardson, M., Roubini, N., 2009. The Financial Crisis of 20072009: Causes and Remedies. Working Paper

Alper, C. E., and Yilmaz, K., 2004. Volatility and Contagion: Evidence from the Istanbul Stock Exchange. Economic Systems 28, 353-367.

Ang A., and Bekaert, G., 2001. Stock Return Predictability: Is it there? Review of Financial Studies 20 (3), 651-707.

Antoniou, A., Koutmos, G., and Percli, A., 2005. Index furure and positive feedback trading: evidence from Major Stock Exchanges. Journal of Empirical Finance 12 (2), 219-238.

Arshanapalli, B., Doukas, J., 1993. International stock market linkages: evidence from the pre- and post-October 1987 period. Journal of Banking and Finance 17, 193-208. 
Bae, K., Karolyi, G., and Stulz, R., 2003. A New Approach to Measuring Financial Contagion. The Review of Financial Studies 16, 717-763.

Baig, T., Goldfajn, I., 1999. Financial market contagion in the Asian crisis. IMF Staff Papers, International Monetary Fund 46 (2), 167-195.

Bartram, S.M., Bodnar, G.M., 2009. No place to hide: The global crisis in equity markets in 2008/2009. Journal of International Money and Finance 28, 1246-1292.

Bekaert, G., Harvey, C.R., and Ng, A., 2005. Market Integration and Contagion. Journal of Business 78 (1), 39-69.

Billio, M., Pelizzon, L., 2003. Contagion and interdependence in stock markets: have they been misdiagnosed? Journal of Economics and Business 55, 405-426.

Bollerslev, T., Chou, R.Y., and Kroner, K.F. 1992. ARCH Modelling in Finance: Review of the Theory and Empirical Evidence. Journal of Econometrica 52, 5-59.

Brooks C., 2008. Introductory Econometrics for Finance. Cambridge University Press, 2ed, ISBN10: 052169468X.

Boschi, M., 2005. International Financial Contagion: Evidence from the Argentina Crisis 2001-2001. Applied Financial Economics 15, 153-163.

Calvo, S., and Reinhart, C., 1995. Capital Inflows to Latin America: Is There Evidence of Contagion Effects? World Bank and International Monetary Fund, mimeo.

Caporale, G.M., Cipollini, A., and Spagnolo, N., 2002. Testing for Contagion: A Conditional Correlation Analysis. Discussion Paper No. 01-2002 Centre for Monetary and Financial Economics, South Bank University.

Cappiello, L., Engle, R., and Sheppard, K., 2006. Asymmetric Dynamics in the Correlations of Global Equity and Bond Returns. Journal of Financial Econometrics 4 (4), 537-572.

Chiang, T.C., Jeon, B.N., and Li, H., 2007. Dynamic Correlation Analysis of Financial Contagion: Evidence from Asian Markets. Journal of International Money and Finance 26, 1206-1228.

Chou, R.Y., 1988. Volatility Persistence and Stock Valuations: Some Empirical Evidence using GARCH. Journal of Econometrics 3, 279-94.

Chudik, A., Fratzscher, M., 2011. Identifying the global transmission of the 2007-2009 financial crisis in a GVAR model. European Economic Review 55, 325-339.

Corsetti, G., Pericoli, M., and Sbracia, M., 2005. Some Contagion, Some Interdependence: More Pitfalls in Tests of Financial Contagion. Journal of International Money and Finance 24, 1177-99.

Coudert, V., Couharde, C., and Mignon, V., 2011. Exchange rate volatility across financial crises. Journal of Banking and Finance 35, 3010-3018.

Doornik, J.A., 1998. Approximations to the Asymptotic Distributions of Cointegration Tests. Journal of Economic Surveys 12, 573-593.

Dornbusch, R., Park, Y.C., and Claessens, S., 2000. Contagion: Understanding How It Spreads. The World Bank Research Observer 15 (2), 177-197. 
Dungey, M., Fry, R., Gonzalez-Hermosillo, B., and Martin, V., 2003. Unanticipated Stocks and Systematic Influence: The Impact of Contagion in Global Equity Markets in 1998. IMF working paper WP/03/84.

Dungey, M., and Martin, V.L., 2001. Contagion Across Financial Markets: An Empirical Assessment. New York Stock Exchange Conference Paper, February 16-17, 2001, Hawaii.

Engle, R., 2002. Dynamic Conditional Correlation: A Simple Class of Multivariate Generalized Autoregressive Conditional Heteroskedasticity Models. Journal of Business and Economic Statistics 20,339-350.

Engle R.F., and Bollerslev, T., 1986. Modeling the Persistence of Conditional Variance. Econometrics Reviews 5, 1-50.

Engle, R.F., and Granger, C., 1987. Co-integration and Error Correction: Representation, Estimation and Testing. Econometrica 55 (2), 251-276.

Engle, R.F., and Sheppard, K., 2001. Theoretical and Empirical Properties of Dynamic Conditional Correlation Multivariate GARCH. NBER working paper no. 8554, www.nber.org/papers/w8554.

Ferna'ndez-Izquierdo, A., and Lafuente, J.A., 2004. International transmission of stock exchange volatility: Empirical evidence from the Asian crisis. Global Finance Journal 15, $125-137$.

Forbes, K., and Rigobon, R., 2002. No Contagion, Only Interdependence: Measuring Stock Market Co-movement. The Journal of Finance 57, 2223-61.

Guo, F., Chen, C.R., Huang, Y.S., 2011. Markets contagion during financial crisis: A regimeswitching approach. International Review of Economics and Finance 20,95-109.

Hon, M.T., Strauss, J., and Yong, S., 2004. Contagion in Financial Markets After September 11 - Myth or Reality? Journal of Financial Research 27, 95-114.

Johansen, S., 1991. Estimation and Hypothesis Testing of Cointegration Vectors in GaussianVector Autoregressive Models. Econometrica 59 (6), 1551-1580.

Johansson, A.C., 2011. Financial Markets in East Asia and Europe during the Global Financial Crisis. The World Economy 1088-1110.

John, K., and Joseph, W., 1985. Dividends, dilution, and taxes: a signalling equilibrium. The Journal of Finance 40, 1053-1070.

Jolliffe, I.T., 2002. Principal Component Analysis, 2nd ed. Springer.

Kaminsky, G.L., and Schmukler, S.L., 1999. What Triggers Market Jitters? A Chronicle of the Asian Crisis. Journal of International Money and Finance 18, 537-560.

Kawai, M., and Khalid, A.M., 2001. Financial Market Contagion: Investigation Cross-market Cross-country Linkages using VARs and Impulse Responses. the World Bank. Washington, DC.

Kenourgios, D., Samitas, A., Paltalidis, N., 2011. Financial crises and stock market contagion in a multivariate time-varying asymmetric framework. Journal of International Financial Markets, Institutions \& Money 21, 92-106. 
Khalid, A.M., and Kawai, M., 2003. Was Financial Market Contagion the Source of Economic Crisis in Asia? Evidence using a Multivariate VAR model. Journal of Asian Economics 14 (1), 133-159.

Khalid, A.M., Rajaguru, G., 2006. Financial Market Contagion or Spillovers Evidence from Asian Crisis using Multivariate GARCH Approach. Bond University Working Paper.

Kleiber, C., Zeileis, A., 2008. Applied Econometrics with R”, Springer, ISBN10: 038773169.

Lee, S., and Kim, K., 1993. Does the October 1987 Crash Strength the Co-movements among National Stock Markets. Review of Financial Economics 3, 89-102.

Longin, F., and Solnik, B., 2001. Extreme Correlation of International Equity Markets. The Journal of Finance 56 (2), 649-676.

Longstaff, F.A., 2011. The subprime credit crisis and contagion in financial markets. Journal of Financial Economics 97, 436-450.

Lutkepohl, H., 2004. Univariate time series analysis, in H. Lutkepohl and M. Kruatzig (eds). Applied Time Series Econometrics. Cambridge University Press, Cambridge, 8-85.

Masson, P., 1998. Contagion: Macroeconomic Models With Multiple Equilibria. Journal of International Money and Finance 18, 587-602.

Masson, P., 1999. Contagion: Monsoonal Effects, Spillovers, and Jumps Between Multiple Equilibria" in Agenor, P.R., Miller, M., Vines, D. and Weber, A. (eds), The Asian Financial Crisis: Causes, Contagion and Consequences. Cambridge University Press, Cambridge, UK.

Masson, P., and Mussa, M., 1995. The Role Of The Fund: Financing And Its Interactions With Adjustments And Surveillance, IMF Working Paper; issue 50.

McInish, T.H., and Lau, S.T., 1993. Comovements of International Equity Returns: A comparison of the pre- and post-October 19, 1987 listing periods. Global Finance Journal 4, $1-19$.

Meric, I., and Meric, G., 1997. Co-movements of European Equity Markets before and after the 1987 crash. Multinational Finance Journal 2, 137-152.

Nourzad, F., Grennier, R.S., 1995. Cointegration Analysis of the Expectations Theory of the Term Structure. Journal of Economics and Business 47, 281-292.

Osterwald-Lenum, M., 1992. A Note with Quantiles of the Asymptotic Distribution of the Maximum Likelihood Cointegration Rank Test Statistics. Oxford Bulletin of Economics and Statistics 55 (3), 461-472.

Penm, J.H.W., Brailsford, T.J., and Terrell, R.D., 1997. The selection of Zero-non-zero Patterned Cointegrating Vectors in Error-Correction Modelling. Econometric Reviews 16 (3), 281-304.

Pericoli, M., and Sbracia, M., 2003. A Primer on Financial Contagion. Journal of Economic Survey 17, 571-608. 
Pesaran, H., and Pick, A., 2003. Econometric Issues in the Analysis of Contagion. Mimeo, University of Cambridge.

Pfaff, B., 2008. Analysis of Integrated and Cointegrated Time Series with R. Springer, New York, NY, ISBN 978-0-387-75966-1. (2nd ed.)

Pritsker, M., 2001. The Channels for Financial Contagion. in Stijn Claessens, Kristin J. Forbes, eds., International Financial Contagion. Boston/Dordrecht/London: Kluwer Academic Publishers.

Rigobon, R., 2003. Identification through Heteroskedasticity. Review of Economics and Statistics 85 (4), 777-792.

Sachs, J., Tornell, A., Velasco, A., 1996. Financial Crises in Emerging Markets: the Lessons from 1995. Brookings Papers on Economic Activity 1, 146-215.

Samarakoon, L.P., 2011. Stock Market Interdependence, Contagion, and the U.S. financial Crisis: The Case of Emerging and Frontier Markets. Journal of International Financial Markets, Institutions \& Money 21, 724-742.

Shlens, J., 2005. A Tutorial on Principal Component Analysis. Sola, Spagnolo and Spagnolo. http//www.cs.princeton.edu/picasso/mats/PCA-Tutorial-Intuition_jp.pdf

White, H., 1980. A Heteroskedasticity-consistent Covariance Matrix Estimator and a Direct Test for Hetroskedasticity. Econometrica 48, 321-55.

Wooldridge, J., 2005. Introductory Econometrics, a Modern Approach. Int. Ed, Cengage Learning, Inc, ISBN10: 0324323484

Yiu, M.S., Alex, H.W., and Choi, D.F., 2010. Dynamic Correlation Analysis of Financial Contagion in Asian Markets in Global Financial Turmoil. Applied Financial Economics 20, 345-354. 


\section{Table 1}

Summary statistics of the MSCI country indices.

The table reports the descriptive statistics of the MSCI daily indices for the crisis sample.

\begin{tabular}{|c|c|c|c|c|c|c|c|c|c|}
\hline \multicolumn{10}{|c|}{ West European Countries } \\
\hline Index & Mean (\%) & $\begin{array}{c}\text { Volatility } \\
(\%)\end{array}$ & Skewness & Kurtosis & $\begin{array}{c}\text { Jarque- } \\
\text { Bera }\end{array}$ & ARCH-LM & ADF & $\begin{array}{c}\text { Phillips- } \\
\text { Perron }\end{array}$ & KPSS \\
\hline AUSTRIA & $-0,02$ & 2,48 & 0,13 & 8,54 & 1336 & 39,13 & $-23,72$ & $-30,96$ & 0,16 \\
\hline BELGIUM & $-0,03$ & 1,94 & $-0,59$ & 9,98 & 2176 & 36,56 & $-21,44$ & $-30,39$ & 0,19 \\
\hline FRANCE & 0,02 & 1,93 & 0,34 & 10,96 & 2770 & 37,54 & $-24,57$ & $-34,22$ & 0,16 \\
\hline GERMANY & 0,03 & 1,91 & 0,32 & 10,29 & 2325 & 48,10 & $-23,59$ & $-33,10$ & 0,18 \\
\hline GREECE & $-0,01$ & 2,24 & 0,07 & 7,66 & 943 & 34,72 & $-22,51$ & $-30,43$ & 0,18 \\
\hline IRELAND & $-0,07$ & 2,54 & $-0,38$ & 9,18 & 1684 & 38,81 & $-23,25$ & $-31,50$ & 0,35 \\
\hline ITALY & $-0,01$ & 1,94 & 0,36 & 10,94 & 2760 & 28,30 & $-13,90$ & $-32,76$ & 0,16 \\
\hline NETHERLANDS & 0,02 & 1,86 & 0,15 & 10,51 & 2456 & 37,46 & $-24,02$ & $-33,16$ & 0,17 \\
\hline PORTUGAL & 0,02 & 1,60 & 0,17 & 13,42 & 4723 & 36,55 & $-22,70$ & $-31,46$ & 0,29 \\
\hline SPAIN & 0,05 & 1,94 & 0,22 & 10,81 & 2658 & 36,52 & $-23,62$ & $-32,80$ & 0,15 \\
\hline SWITZERLAND & 0,02 & 1,52 & 0,32 & 9,12 & 1646 & 36,87 & $-25,16$ & $-33,10$ & 0,17 \\
\hline UK & $-0,11$ & 2,38 & $-0,18$ & 13,70 & 4984 & 38,56 & $-19,70$ & $-27,86$ & 0,13 \\
\hline \multicolumn{10}{|c|}{ East European Countries } \\
\hline CROATIA & 0,06 & 1,81 & 0,06 & 8,55 & 1339 & 43,16 & $-22,87$ & $-27,87$ & $0,442^{*}$ \\
\hline $\begin{array}{l}\text { CZECH } \\
\text { REPUBLIC }\end{array}$ & 0,05 & 2,36 & 0,39 & 16,23 & 7636 & 38,22 & $-24,20$ & $-30,84$ & 0,12 \\
\hline ESTONIA & $-0,05$ & 2,06 & 0,26 & 8,06 & 1123 & 39,13 & $-20,94$ & $-29,04$ & 0,16 \\
\hline HUNGARY & 0,04 & 2,93 & 0,39 & 10,81 & 2675 & 42,65 & $-19,10$ & $-28,58$ & 0,11 \\
\hline POLAND & 0,03 & 2,58 & 0,05 & 6,58 & 558 & 44,79 & $-22,41$ & $-29,56$ & 0,13 \\
\hline ROMANIA & 0,00 & 2,67 & $-0,98$ & 14,72 & 6139 & 40,85 & $-22,71$ & $-30,60$ & 0,20 \\
\hline RUSSIA & 0,05 & 3,21 & 0,26 & 15,39 & 6680 & 40,60 & $-22,24$ & $-29,94$ & 0,15 \\
\hline SLOVENIA & 0,04 & 1,73 & $-0,22$ & 8,73 & 1436 & 48,20 & $-18,35$ & $-27,47$ & $0,602^{* *}$ \\
\hline \multicolumn{10}{|c|}{ Nordic Countries } \\
\hline DENMARK & 0,03 & 1,90 & $-0,08$ & 9,67 & 1934 & 37,80 & $-23,43$ & $-31,23$ & 0,16 \\
\hline FINLAND & 0,01 & 2,19 & 0,25 & 7,27 & 803 & 36,77 & $-24,10$ & $-33,36$ & 0,24 \\
\hline NORWAY & 0,05 & 2,79 & $-0,12$ & 7,40 & 844 & 39,68 & $-24,45$ & $-33,21$ & 0,14 \\
\hline SWEDEN & 0,03 & 2,41 & 0,41 & 7,54 & 924 & 38,43 & $-25,24$ & $-32,54$ & 0,15 \\
\hline \multicolumn{10}{|c|}{ MENA Countries } \\
\hline TURKEY & 0,05 & 2,90 & 0,00 & 6,48 & 525 & 46,82 & $-21,70$ & $-30,31$ & 0,10 \\
\hline BAHRAIN & $-0,09$ & 1,55 & $-2,54$ & 43,90 & 73835 & 40,58 & $-22,04$ & $-30,96$ & $0,394^{*}$ \\
\hline ISRAEL & 0,03 & 1,25 & $-0,64$ & 7,02 & 774 & 38,81 & $-22,90$ & $-31,34$ & 0,16 \\
\hline JORDAN & $-0,06$ & 1,49 & $-0,57$ & 9,60 & 1949 & 38,54 & $-21,53$ & $-29,91$ & 0,09 \\
\hline KUWAIT & $-0,03$ & 1,78 & $-0,85$ & 10,95 & 2871 & 38,49 & $-21,14$ & $-31,44$ & 0,22 \\
\hline LEBANON & 0,03 & 1,86 & 0,20 & 14,15 & 5408 & 49,75 & $-23,46$ & $-27,44$ & 0,09 \\
\hline OMAN & 0,00 & 1,64 & $-0,92$ & 21,17 & 14495 & 36,66 & $-21,12$ & $-28,97$ & 0,16 \\
\hline QATAR- & $-0,03$ & 2,00 & $-0,35$ & 10,46 & 2441 & 38,62 & $-21,55$ & $-29,58$ & 0,15 \\
\hline UAE & 0,01 & 1,89 & 0,23 & 11,22 & 2946 & 37,36 & $-24,46$ & $-33,79$ & 0,20 \\
\hline EGYPT & 0,03 & 1,98 & $-0,89$ & 9,69 & 2079 & 41,22 & $-21,15$ & $-28,22$ & 0,12 \\
\hline MOROCCO & 0,07 & 1,34 & $-0,30$ & 5,69 & 330 & 40,98 & $-20,85$ & $-25,43$ & $0,68^{* *}$ \\
\hline TUNISIA & 0,06 & 1,11 & 0,27 & 11,28 & 2991 & 38,75 & $-20,40$ & $-29,29$ & 0,10 \\
\hline \multicolumn{10}{|c|}{ African Countries } \\
\hline KENYA & 0,01 & 1,61 & 0,65 & 12,11 & 3683 & 38,53 & $-18,16$ & $-21,90$ & 0,18 \\
\hline MAURITIUS & 0,10 & 1,63 & 0,40 & 11,48 & 3152 & 39,90 & $-21,05$ & $-28,75$ & 0,25 \\
\hline NIGERIA & 0,00 & 1,61 & $-0,22$ & 5,91 & 376 & 38,69 & $-16,16$ & $-17,74$ & $0,506^{* *}$ \\
\hline $\begin{array}{l}\text { SOUTH } \\
\text { AFRICA }\end{array}$ & 0,05 & 2,40 & $-0,15$ & 6,40 & 506 & 40,02 & $-23,45$ & $-30,59$ & 0,09 \\
\hline \multicolumn{10}{|c|}{ South and Centrial Asian Countries } \\
\hline CHINA & 0,11 & 2,42 & 0,23 & 8,02 & 1105 & 46,02 & $-22,93$ & $-32,02$ & 0,16 \\
\hline HONG KONG & 0,04 & 1,76 & 0,07 & 9,01 & 1570 & 51,80 & $-22,49$ & $-33,17$ & 0,13 \\
\hline INDIA & 0,08 & 2,38 & 0,43 & 10,81 & 2683 & 43,53 & $-22,41$ & $-30,27$ & 0,13 \\
\hline KAZAKHSTAN & 0,08 & 3,13 & 0,56 & 9,65 & 1978 & 38,83 & $-17,77$ & $-35,12$ & 0,14 \\
\hline KOREA & 0,04 & 2,46 & 0,68 & 25,42 & 21932 & 37,60 & $-21,58$ & $-31,63$ & 0,13 \\
\hline PAKISTAN & $-0,04$ & 1,99 & $-0,43$ & 5,31 & 264 & 38,62 & $-18,88$ & $-26,64$ & 0,13 \\
\hline SRI LANKA & 0,04 & 1,57 & 2,64 & 30,32 & 33637 & 37,57 & $-19,53$ & $-26,13$ & 0,19 \\
\hline TAIWAN & 0,03 & 1,74 & $-0,10$ & 5,44 & 260 & 38,42 & $-20,94$ & $-31,40$ & 0,13 \\
\hline THAILAND & 0,04 & 2,03 & $-0,69$ & 12,17 & 3739 & 45,60 & $-21,44$ & $-32,72$ & 0,12 \\
\hline
\end{tabular}




\begin{tabular}{|c|c|c|c|c|c|c|c|c|c|}
\hline \multicolumn{10}{|c|}{ Asian Pacific Countries } \\
\hline AUSTRALIA & 0,05 & 2,17 & $-0,64$ & 8,93 & 1599 & 39,52 & $-22,79$ & $-32,67$ & 0,16 \\
\hline INDONESIA & 0,11 & 2,35 & $-0,04$ & 8,78 & 1452 & 39,05 & $-20,67$ & $-28,09$ & 0,13 \\
\hline JAPAN & $-0,02$ & 1,71 & 0,11 & 7,87 & 1032 & 38,59 & $-26,62$ & $-36,49$ & 0,09 \\
\hline MALAYSIA & 0,05 & 1,23 & $-0,63$ & 10,14 & 2284 & 39,43 & $-22,22$ & $-28,73$ & 0,23 \\
\hline $\begin{array}{l}\text { NEW } \\
\text { ZEALAND }\end{array}$ & ? & 177 & 031 & 712 & 750 & 3703 & 2400 & 3005 & \\
\hline PHILIPPINES & 0,06 & 1,89 & $-0,38$ & 7,81 & 1030 & 39,38 & $-21,78$ & $-28,57$ & 0,20 \\
\hline SINGAPORE & 0,05 & 1,79 & $-0,06$ & 6,71 & 600 & 47,87 & $-22,00$ & $-31,98$ & 0,17 \\
\hline \multicolumn{10}{|c|}{ North American Countries } \\
\hline CANADA & 0,04 & 2,02 & $-0,52$ & 9,76 & 2032 & 76,73 & $-24,90$ & $-31,38$ & 0,11 \\
\hline MEXICO & 0,05 & 2,23 & 0,29 & 9,01 & 1585 & 63,39 & $-22,61$ & $-29,43$ & 0,13 \\
\hline$\overline{U S A}$ & 0,00 & 1,63 & 0,02 & 11,97 & 3496 & 67,32 & $-19,89$ & $-36,91$ & 0,14 \\
\hline \multicolumn{10}{|c|}{ South American Countries } \\
\hline ARGENTINA & 0,04 & 2,54 & $-0,38$ & 9,53 & 1880 & 55,18 & $-22,87$ & $-31,45$ & 0,16 \\
\hline BRAZIL & 0,12 & 2,92 & 0,00 & 9,56 & 1869 & 53,41 & $-23,62$ & $-31,21$ & 0,10 \\
\hline CHILE & 0,07 & 1,75 & 0,21 & 17,88 & 9633 & 43,53 & $-22,10$ & $-30,19$ & 0,12 \\
\hline COLOMBIA & 0,07 & 2,24 & 0,00 & 12,06 & 3565 & 45,56 & $-22,54$ & $-29,69$ & 0,08 \\
\hline PERU & 0,13 & 2,56 & $-0,03$ & 7,11 & 734 & 36,44 & $-23,05$ & $-30,66$ & 0,14 \\
\hline \multicolumn{10}{|c|}{$\begin{array}{l}\text { Note: All results in the table are performed on the returns of the indices. The ADF and PP tests have been performed on the no time trend } \\
\text { models of the test s. KPSS test performs a unit root test with the null of st ationarity and the alternative of a unit root. Si gnificance is not } \\
\text { shown for Jarque-Bera, ARCH-LM, ADF and PP test s, as for all indices we find significance at } 1 \% \text { significance level in each of these tests. } \\
\text { For the KPSS test: } * * * * *, * \text { imply significance at } 1 \%, 5 \% \text { and } 10 \% \text { respectively. } \\
{ }^{*} \text { The test results for the Jarque-Bera, ARCH-LM, ADF and PP tests are not reported in the table as for each index we obtain significant } \\
\text { results at } 1 \% \text {. For the KPSS test } * * *, * *, * \text { indicate significance at } 1 \%, 5 \% \text { and } 10 \% \text { significance level. }\end{array}$} \\
\hline
\end{tabular}

\section{Table 2}

\section{Results for the mean model}

This table presents the results foreq. 1. $r_{i, t}=\alpha_{0}+\beta_{1} r_{i, t-1}+\beta_{2} r_{t-1}^{U S}+\varepsilon_{i, t}$ Where, $r_{i, t 1}$ is the country specific lag return, $r_{t-1}^{U S}$ is the return on the US market at time $t-1 ;$ and $\varepsilon_{i, t} \mid \mathfrak{J}_{t-1} \approx \mathrm{N}\left(0, \mathrm{H}_{\mathrm{t}}\right)$.

\begin{tabular}{|c|c|c|c|c|c|c|c|}
\hline \multicolumn{4}{|c|}{ South American Countries } & \multicolumn{4}{|c|}{ North American Countries } \\
\hline Country & $\alpha_{0}$ & $\beta_{1}$ & $\beta_{2}$ & Country & $\alpha_{0}$ & $\beta_{1}$ & $\beta_{2}$ \\
\hline ARGENTINA & 0,04 & $-0,096^{* *}$ & $0,35^{* * *}$ & CANADA & 0,04 & $-0,21^{* * *}$ & $0,42^{* * *}$ \\
\hline BRAZIL & 0,14 & $-0,17^{* * *}$ & $0,52^{* * *}$ & MEXICO & 0,05 & $-0,05$ & $0,26^{* * *}$ \\
\hline CHILE & 0,07 & $-0,073^{*}$ & $0,26 * * *$ & USA & 0,00 & $-0,13^{* * *}$ & \\
\hline COLOMBIA & 0,07 & $-0,02$ & $0,43 * * *$ & \multicolumn{4}{|c|}{ Nordic Countries } \\
\hline PERU & 0,14 & $-0,078^{* *}$ & $0,35^{* * *}$ & FINLAND & 0,007 & $-0,21 * * *$ & $0,54^{* * *}$ \\
\hline \multicolumn{4}{|c|}{ West European Countries } & DENMARK & 0,036 & $-0,16 * * *$ & $0,52 * * *$ \\
\hline AUSTRIA & $-0,029$ & $-0,13^{* * *}$ & $0,63^{* * *}$ & NORWAY & 0,058 & $-0,19^{* * *}$ & $0,65^{* * *}$ \\
\hline BELGIUM & $-0,031$ & $-0,084 * *$ & $0,37^{* * *}$ & SWEDEN & 0,030 & $-0,009$ & $-0,082^{*}$ \\
\hline FRANCE & 0,022 & $-0,33 * * *$ & $0,60 * * *$ & \multicolumn{4}{|c|}{ Central European Countries } \\
\hline GERMANY & 0,033 & $-0,26 * * *$ & $0,47^{* * *}$ & CROATIA & 0,056 & $0,055^{* *}$ & $0,45^{* * *}$ \\
\hline GREECE & $-0,016$ & $-0,055^{*}$ & $0,49^{* * *}$ & CZECH REP. & 0,052 & $-0,089^{* * *}$ & $0,60^{* * *}$ \\
\hline IRELAND & $-0,086$ & $-0,13^{* * *}$ & $0,54 * * *$ & ESTONIA & $-0,050$ & $0,058^{*}$ & $0,46 * * *$ \\
\hline ITALY & $-0,012$ & $-0,24 * * *$ & $0,53^{* * *}$ & HUNGARY & 0,034 & $-0,025$ & $0,64 * * *$ \\
\hline NETHERLANDS & 0,021 & $-0,27 * * *$ & $0,51 * * *$ & POLAND & 0,027 & $-0,030$ & $0,51^{* * *}$ \\
\hline PORTUGAL & 0,020 & $-0,13^{* * *}$ & $0,40^{* * *}$ & ROMANIA & $-0,004$ & $-0,028$ & $0,55^{* * *}$ \\
\hline SPAIN & 0,056 & $-0,25 * * *$ & $0,53^{* * *}$ & RUSSIA & 0,048 & $-0,027$ & $0,52^{* * *}$ \\
\hline SWITZERLAND & 0,021 & $-0,24 * * *$ & $0,43^{* * *}$ & SLOVENIA & 0,035 & $0,087^{* * *}$ & $0,48^{* * *}$ \\
\hline UK & $-0,097$ & $0,13^{* * *}$ & $0,38^{* * *}$ & \multicolumn{4}{|c|}{ MENA Countries } \\
\hline \multicolumn{4}{|c|}{ African Countries } & TURKEY & 0,048 & $-0,069 * *$ & $0,59 * * *$ \\
\hline KENYA & 0,009 & $0,37^{* * *}$ & $0,13^{* * *}$ & BAHRAIN & $-0,083^{*}$ & 0,05 & $0,11^{* * *}$ \\
\hline MAURITIUS & $0,089 *$ & $0,11^{* * *}$ & $0,17^{* * *}$ & JORDAN & $-0,06$ & $0,080^{* *}$ & $0,19 * * *$ \\
\hline NIGERIA & $-0,003$ & $0,54^{* * *}$ & $0,052^{*}$ & ISRAEL & 0,03 & $-0,04$ & $0,19 * * *$ \\
\hline SOUTH & 0,049 & $-0,11^{* * *}$ & $0,67^{* * *}$ & KUWAIT & $-0,03$ & 0,03 & $0,12^{* * *}$ \\
\hline
\end{tabular}




\begin{tabular}{|c|c|c|c|c|c|c|c|}
\hline AFRICA & & & & & & & \\
\hline \multicolumn{4}{|c|}{ Asian Pacific Countries } & LEBANON & 0,02 & $0,15^{* * *}$ & $0,12^{* * *}$ \\
\hline AUSTRALIA & 0,050 & $-0,15^{* * *}$ & $0,84^{* * *}$ & OMAN & 0,00 & $0,11^{* * *}$ & $0,25^{* * *}$ \\
\hline INDONESIA & 0,10 & $0,089 * * *$ & $0,55^{* * *}$ & QATAR & $-0,02$ & $0,093^{* * *}$ & $0,34^{* * *}$ \\
\hline JAPAN & $-0,02$ & $-0,12^{* * *}$ & $0,56^{* * *}$ & UAE & 0,00 & $-0,31^{* * *}$ & $0,57^{* * *}$ \\
\hline MALAYSIA & 0,05 & $0,068^{* *}$ & $0,29 * * *$ & EGYPT & 0,019 & $0,10^{* * *}$ & $0,40^{* * *}$ \\
\hline $\begin{array}{l}\text { NEW } \\
\text { ZEALAND }\end{array}$ & $-0,02$ & $-0,056 * *$ & $0,62 * * *$ & MOROCCO & 0,051 & $0,22 * * *$ & $0,14^{* * *}$ \\
\hline PHILIPPINES & 0,05 & $0,090^{* * *}$ & $0,66^{* * *}$ & TUNISIA & 0,052 & $0,085^{* * *}$ & $0,14^{* * *}$ \\
\hline SINGAPORE & 0,06 & $-0,11^{* * *}$ & $0,43^{* * *}$ & & & & \\
\hline \multicolumn{8}{|c|}{ South and Central Asian Countries } \\
\hline CHINA & 0,11 & $-0,094^{* * *}$ & $0,63^{* * *}$ & KOREA & 0,04 & $-0,064^{* *}$ & $0,62^{* * *}$ \\
\hline HONG KONG & 0,04 & $-0,13 * * *$ & $0,48^{* * *}$ & PAKISTAN & $-0,03$ & $0,19 * * *$ & $0,10^{* * *}$ \\
\hline INDIA & 0,08 & $-0,02$ & $0,39 * * *$ & SRI LANKA & 0,03 & $0,21^{* * *}$ & $0,11^{* * *}$ \\
\hline \multirow[t]{2}{*}{ KAZAKHSTAN } & 0,11 & $-0,13^{* * *}$ & $0,62^{* * *}$ & TAIWAN & 0,02 & $-0,02$ & $0,44^{* * *}$ \\
\hline & & & & THAILAND & 0,04 & $-0,089 * * *$ & $0,36^{* * *}$ \\
\hline
\end{tabular}

Note: $\boldsymbol{\alpha}_{0}, \boldsymbol{\beta}_{1}$ represent the constant and the autoregressive term and $\boldsymbol{\beta}_{2}$ represents the lagged US return. $* * *, * *, *$ represent significance at $1 \%, 5 \%$ and $10 \%$ levels. 

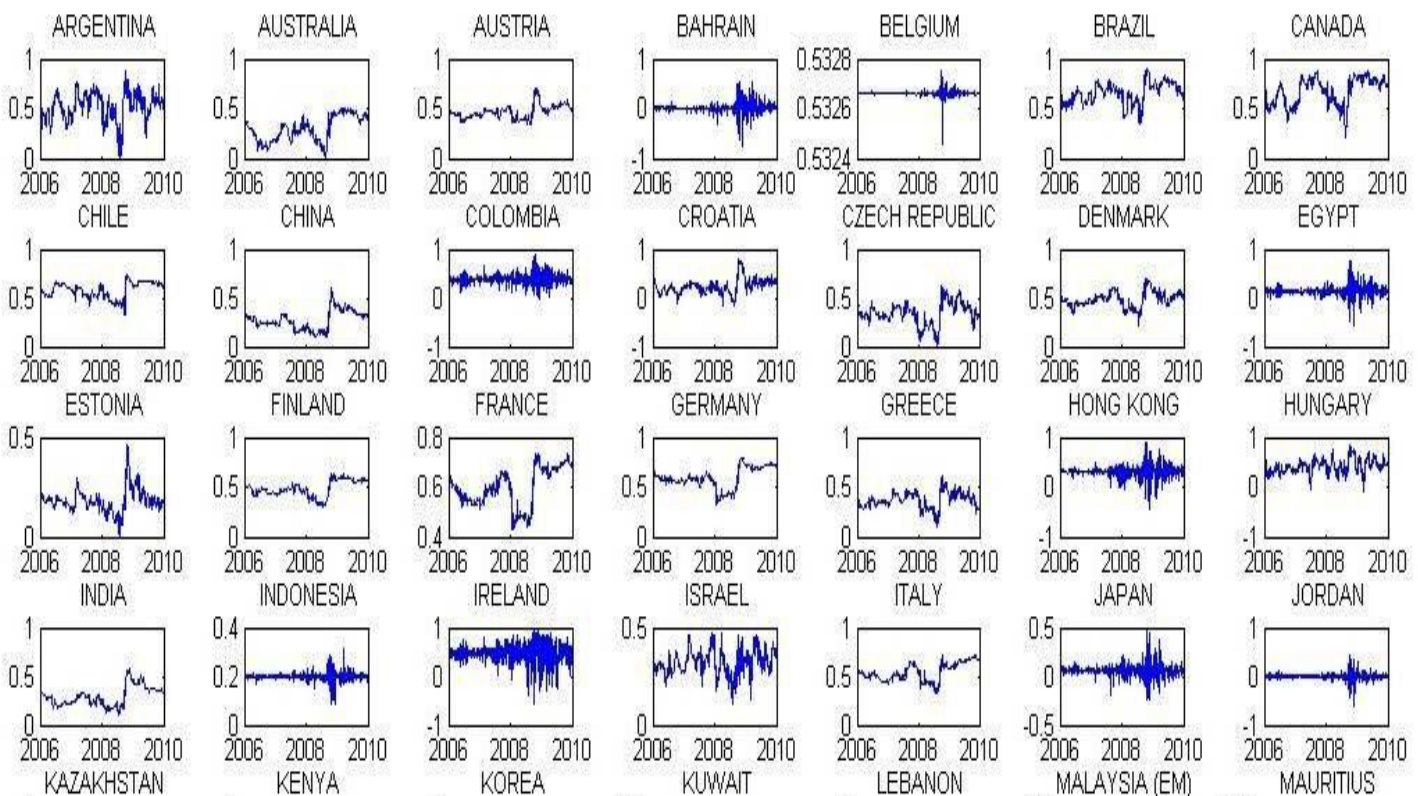

IRELAND
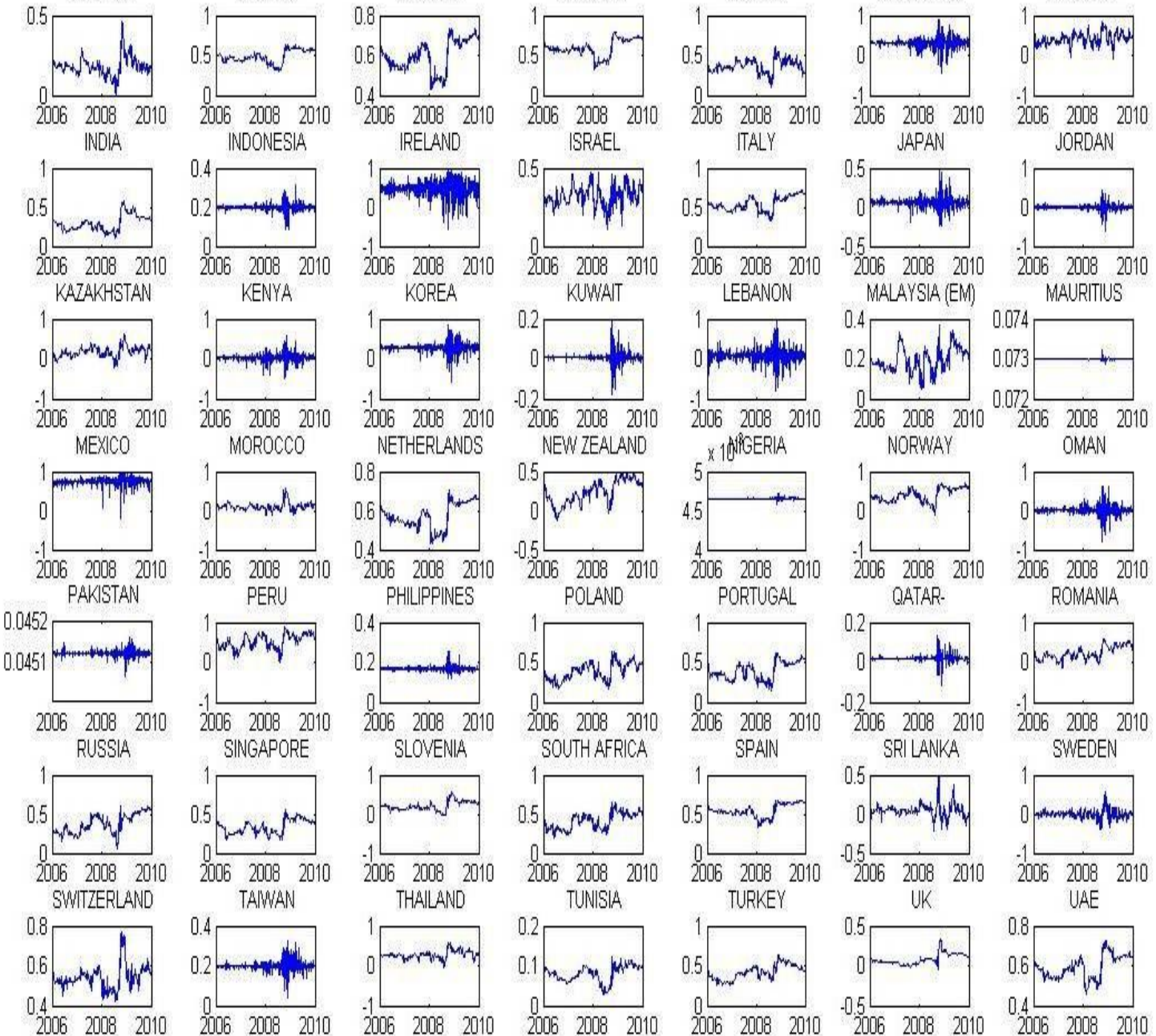

$\frac{0.1 \text { mom }}{2006 \quad 20082010}$
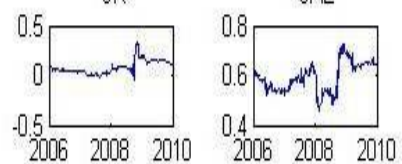

Figure 1: Dynamic Condition Correlation between the US and the rest of the Countries 


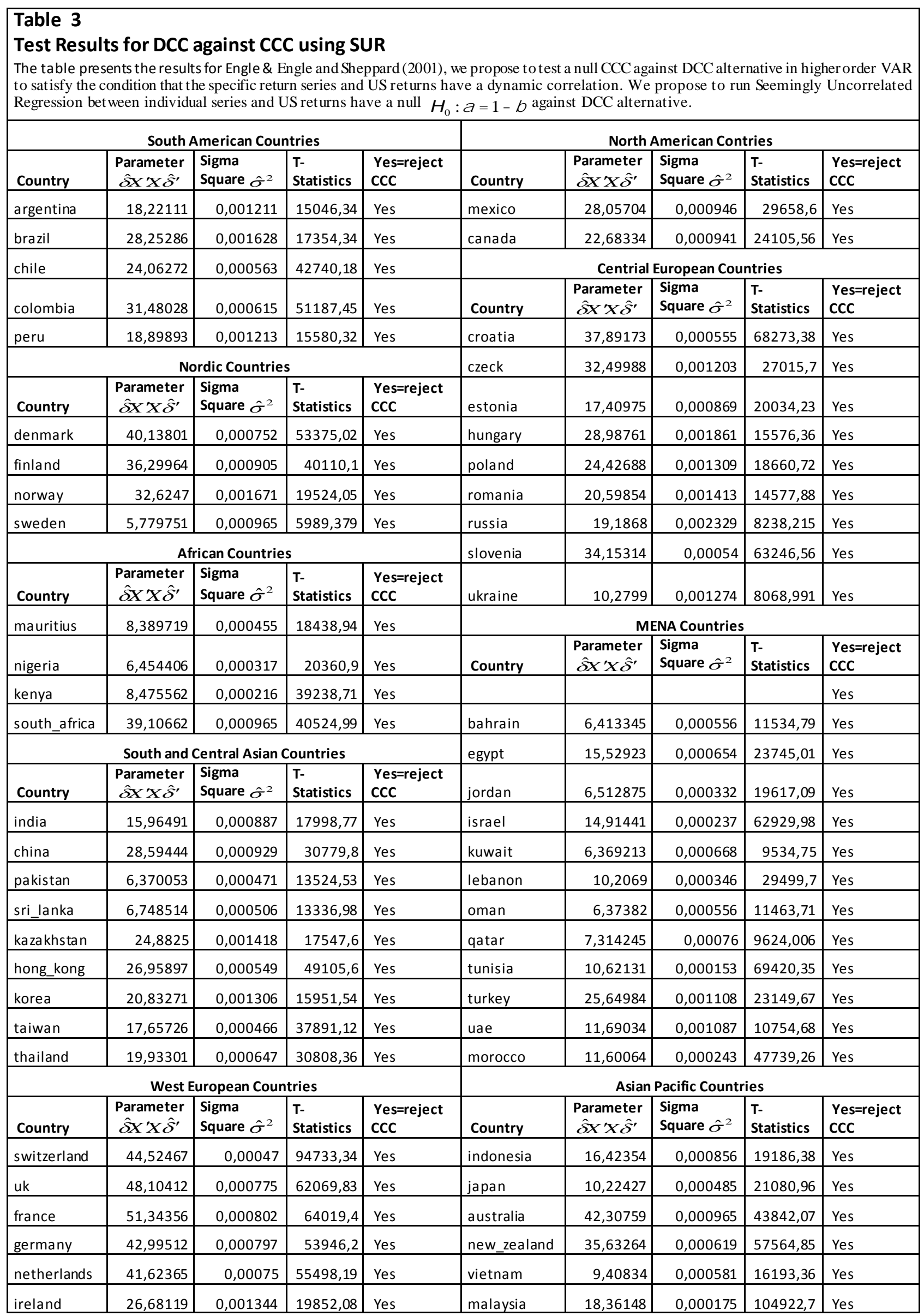




\begin{tabular}{l|r|r|r|l|l|l|r|r|r|l|} 
italy & 42,72924 & 0,000872 & 49001,42 & Yes & philippines & 20,4042 & 0,00048 & 42508,74 & Yes \\
\hline austria & 32,88892 & 0,001435 & 22919,11 & Yes & singapore & 24,90769 & 0,000595 & 41861,67 & Yes \\
\hline belgium & 22,54482 & 0,00076 & 29664,24 & Yes & & & & & \\
\hline portugal & 34,1309 & 0,000533 & 64035,46 & Yes & & & & & \\
\hline spain & 43,08335 & 0,00081 & 53189,32 & Yes & & & & & \\
\hline $\begin{array}{l}\mathrm{H}_{0} \text { : Constant Correlation }(\alpha=1-\beta) \text { and } \mathrm{H}_{1} \text { : Dynamic Correlation. Critical value for Chi' }{ }^{2} \text { at } 5 \% \text { level is } 7,8 \text {, and at } 1 \% \text { level is } 11,3 \text {. 'Yes' means it } \\
\text { rejects CCC. }\end{array}$
\end{tabular}

Table 4 - Results for AR(1) model for the DCC (eq. 7)

\begin{tabular}{|c|c|c|c|c|c|c|c|c|c|}
\hline \multicolumn{5}{|c|}{ West European Countries } & \multicolumn{5}{|c|}{ East European Countries } \\
\hline Country & $\gamma_{0}$ & $\gamma_{1}$ & $\delta$ & $\mathrm{R}^{2}$ & Country & $\gamma_{0}$ & $\gamma_{1}$ & $\delta$ & $\mathrm{R}^{2}$ \\
\hline AUSTRIA & $-0,0004$ & $0,96^{* * *}$ & $0,0030 * * *$ & 0,95 & CROATIA & $-0,0024^{*}$ & $0,92 * * *$ & $0,0085^{* * *}$ & 0,88 \\
\hline BELGIUM & $0,013^{* * *}$ & 0,0000 & $2,8 \mathrm{E}-07^{*}$ & 0,00 & CZECH REP. & $-0,0006$ & $0,95 * * *$ & $0,0033^{* *}$ & 0,92 \\
\hline FRANCE & $-0,0004$ & $0,96^{* * *}$ & $0,0043^{* * *}$ & 0,97 & ESTONIA & $-0,0003$ & $0,95^{* * *}$ & $0,0017^{* * *}$ & 0,94 \\
\hline GERMANY & $-0,0006$ & $0,96^{* * *}$ & $0,0051^{* * *}$ & 0,96 & HUNGARY & $-0,0018$ & $0,90 * * *$ & $0,0075^{* * *}$ & 0,83 \\
\hline GREECE & $-0,0002$ & $0,96^{* * *}$ & $0,0018^{*}$ & 0,93 & ROMANIA & $-0,0015$ & $0,95^{* * *}$ & $0,0052^{* * *}$ & 0,93 \\
\hline IRELAND & $0,011^{* * *}$ & $0,16^{* * *}$ & 0,0098 & 0,03 & RUSSIA & $-0,0005$ & $0,97^{* * *}$ & $0,0032^{* *}$ & 0,96 \\
\hline ITALY & $-0,0005$ & $0,96^{* * *}$ & $0,0041^{* * *}$ & 0,96 & POLAND & $-0,0005$ & $0,96 * * *$ & $0,0031^{* *}$ & 0,94 \\
\hline NETHERLANDS & $-0,0001$ & $0,95^{* * *}$ & $0,0050^{* * *}$ & 0,98 & SLOVENIA & $-0,0014^{* *}$ & $0,96 * * *$ & $0,0046^{* * *}$ & 0,96 \\
\hline PORTUGAL & $-0,0004$ & $0,97 * * *$ & $0,0032 * *$ & 0,97 & \multicolumn{5}{|c|}{ Nordic Countries } \\
\hline SPAIN & $-0,0002$ & $0,96 * * *$ & $0,0048^{* * *}$ & 0,97 & DENMARK & $-0,0002$ & $0,95^{* * *}$ & $0,0026^{* *}$ & 0,93 \\
\hline SWITZERLAND & $-0,0004$ & $0,95^{* * *}$ & $0,0032^{* * *}$ & 0,93 & NORWAY & $-0,0013$ & $0,95^{* * *}$ & $0,0064^{* * *}$ & 0,94 \\
\hline UK & $-0,0002$ & $0,98^{* * *}$ & $0,00073^{* *}$ & 0,98 & FINLAND & $-0,0005$ & $0,97^{* * *}$ & $0,0032^{* * *}$ & 0,97 \\
\hline \multicolumn{5}{|c|}{ MENA Countries } & SWEDEN & 0,0000 & $0,82^{* * *}$ & $-0,0001$ & 0,68 \\
\hline TURKEY & $-0,0001$ & $0,98^{* * *}$ & $0,0011^{*}$ & 0,97 & \multicolumn{5}{|c|}{ South and Central Asian Countries } \\
\hline EGYPT & $0,0026^{* *}$ & $-0,0171$ & $0,0049^{* *}$ & 0,01 & CHINA & $-0,0005$ & $0,96^{* * *}$ & $0,0024^{* * *}$ & 0,96 \\
\hline MOROCCO & $-0,0013^{*}$ & $0,93^{* * *}$ & $0,0033^{* *}$ & 0,89 & HONG KONG & 0,0010 & 0,0152 & $0,0084^{* * *}$ & 0,01 \\
\hline TUNISIA & $-0,00018^{* * *}$ & $0,98^{* * *}$ & $0,00055^{* *}$ & 0,98 & INDIA & $-0,00058^{* * *}$ & $0,97^{* * *}$ & $0,0023^{* * *}$ & 0,97 \\
\hline BAHRAIN & $-0,0063^{* * *}$ & $-0,0040$ & $0,0043^{*}$ & 0,00 & KAZAKHSTAN & $-0,0010$ & $0,94^{* * *}$ & $0,0031^{* *}$ & 0,90 \\
\hline ISRAEL & 0,0004 & $0,94^{* * *}$ & 0,0015 & 0,88 & KOREA & $0,0028^{* * *}$ & $-0,0053$ & 0,0026 & 0,00 \\
\hline JORDAN & $-0,0008$ & $\begin{array}{c}-2,09 \mathrm{E}- \\
04\end{array}$ & 0,0006 & 0,00 & PAKISTAN & $0,00051 * * *$ & $-0,0002$ & $\begin{array}{c}-3,83762 \mathrm{E}- \\
08\end{array}$ & 0,00 \\
\hline KUWAIT & 0,0002 & $-0,001$ & 0,0003 & 0,00 & SRI LANKA & 0,0000 & $0,93^{* * *}$ & 0,0001 & 0,86 \\
\hline LEBANON & $-0,00909939$ & $-0,0116$ & 0,0065 & 0,00 & TAIWAN & $0,0027^{* * *}$ & 0,0170 & $0,00095^{* *}$ & 0,01 \\
\hline OMAN & $-0,0009$ & 0,0031 & $-0,0022$ & 0,00 & THAILAND & $-0,0007$ & $0,94^{* * *}$ & $0,0033^{* * *}$ & 0,92 \\
\hline QATAR & $0,00057^{* * *}$ & $-0,0012$ & 0,0002 & 0,00 & \multicolumn{5}{|c|}{ Asian Pacific Countries } \\
\hline UAE & $-0,0001$ & $0,97^{* * *}$ & $0,0025^{* * *}$ & 0,97 & AUSTRALIA & $-0,0009$ & $0,97^{* * *}$ & $0,0037^{* * *}$ & 0,96 \\
\hline \multicolumn{5}{|c|}{ African Countries } & INDONESIA & $0,0037 * * *$ & 0,0035 & 0,0003 & 0,00 \\
\hline KENYA & $-0,0027^{*}$ & $0,36^{* * *}$ & $0,0045^{*}$ & 0,13 & JAPAN & $-0,0009$ & $0,33^{* * *}$ & $-0,0004$ & 0,11 \\
\hline MAURITIUS & $0,0029^{* * *}$ & 0,0000 & 0,0000 & 0,00 & MALAYSIA & $-0,0004$ & $0,96^{* * *}$ & $0,0020^{* *}$ & 0,94 \\
\hline NIGERIA & $-0,00040^{* * *}$ & $-0,0004$ & 0,0000 & 0,00 & $\begin{array}{l}\text { NEW } \\
\text { ZEALAND }\end{array}$ & $-0,0007$ & $0,96 * * *$ & $0,0034 * *$ & 0,95 \\
\hline SOUTH AFRICA & $-0,0005$ & $0,96^{* * *}$ & $0,0028^{* *}$ & 0,95 & PHILIPPINES & $0,0040^{* * *}$ & 0,0099 & 0,0002 & 0,00 \\
\hline & & & & & SINGAPORE & $-0,0006$ & $0,97^{* *}$ & $0,0029^{* * *}$ & 0,97 \\
\hline \multicolumn{5}{|c|}{ North American Countries } & \multicolumn{5}{|c|}{ South American Countries } \\
\hline CANADA & $-0,0004$ & $0,94^{* * *}$ & $0,0058^{* *}$ & 0,91 & ARGENTINA & 0,0006 & $0,93^{* * *}$ & 0,0029 & 0,86 \\
\hline \multirow[t]{4}{*}{ MEXICO } & $0,013^{* * *}$ & $0,19 * * *$ & $0,0088^{*}$ & 0,04 & BRAZIL & $-0,0003$ & $0,95^{* * *}$ & $0,0037^{*}$ & 0,91 \\
\hline & & & & & CHILE & 0,0000 & $0,97^{* * *}$ & $0,0021^{*}$ & 0,95 \\
\hline & & & & & COLOMBIA & $0,0075^{* * *}$ & $-0,0224$ & $0,0056^{*}$ & 0,00 \\
\hline & & & & & PERU & $-0,0011$ & $0,93^{* * *}$ & $0,0067^{* *}$ & 0,89 \\
\hline
\end{tabular}


Table 5 - The five largest principal components of stock market returns in different regions. Returns used are from $1^{\text {st }}$ January 2006 to $31^{\text {st }}$ December 2010

\begin{tabular}{|c|c|c|c|c|c|}
\hline Western Europé & 1st princ.comp & 2nd princ.comp & 3rd princ.comp & 4th princ.comp & $\begin{array}{c}5 \text { th } \\
\text { princ.comp }\end{array}$ \\
\hline Eigenvalue & 35,8 & 5,4 & 2,6 & 2,0 & 1,4 \\
\hline Cumulative eigenvalue & 35,8 & 41,2 & 43,8 & 45,8 & 47,2 \\
\hline Variance proportion & 0,712 & 0,107 & 0,052 & 0,039 & 0,028 \\
\hline Cumulative proportion & 0,712 & 0,819 & 0,871 & 0,910 & 0,938 \\
\hline
\end{tabular}

\begin{tabular}{|l|c|c|c|c|c|}
\cline { 2 - 6 } \multicolumn{1}{c|}{ Eastern Europé } & 1st princ.comp & 2nd princ.comp & 3rd princ.comp & 4th princ.comp & $\begin{array}{c}5 \text { th } \\
\text { princ.comp }\end{array}$ \\
\hline Eigenvalue & 30,2 & 4,8 & 3,7 & 3,3 & 2,1 \\
\hline Cumulative eigenvalue & 30,2 & 35,0 & 38,7 & 41,9 & 44,1 \\
\hline Variance proportion & 0,618 & 0,098 & 0,076 & 0,067 & 0,043 \\
\hline Cumulative proportion & 0,618 & 0,716 & 0,792 & 0,859 & 0,903 \\
\hline
\end{tabular}

\begin{tabular}{|l|c|c|c|c|}
\cline { 2 - 5 } \multicolumn{1}{l|}{ Nordic } & 1st princ.comp & 2nd princ.comp & 3rd princ.comp & 4th princ.comp \\
\hline Eigenvalue & 13,8 & 5,8 & 1,5 & 0,8 \\
\hline Cumulative eigenvalue & 13,8 & 19,7 & 21,2 & 22,0 \\
\hline Variance proportion & 0,628 & 0,265 & 0,069 & 0,038 \\
\hline Cumulative proportion & 0,628 & 0,893 & 0,962 & 1,000 \\
\hline
\end{tabular}

\begin{tabular}{|c|c|c|c|c|c|}
\hline MENA & 1st princ.comp & 2nd princ.comp & 3rd princ.comp & 4th princ.comp & $\begin{array}{c}\text { 5th } \\
\text { princ.comp } \\
\end{array}$ \\
\hline Eigenvalue & 12,2 & 7,4 & 3,2 & 2,9 & 2,4 \\
\hline Cumulative eigenvalue & 12,2 & 19,6 & 22,8 & 25,8 & 28,2 \\
\hline Variance proportion & 0,318 & 0,192 & 0,084 & 0,077 & 0,062 \\
\hline Cumulative proportion & 0,318 & 0,510 & 0,594 & 0,671 & 0,732 \\
\hline
\end{tabular}

\begin{tabular}{|c|c|c|c|c|}
\hline Africa & 1st princ.comp & 2nd princ.comp & 3rd princ.comp & 4th princ.comp \\
\hline Eigenvalue & 5,9 & 2,9 & 2,6 & 2,3 \\
\hline Cumulative eigenvalue & 5,9 & 8,8 & 11,4 & 13,6 \\
\hline Variance proportion & 0,431 & 0,212 & 0,191 & 0,166 \\
\hline Cumulative proportion & 0,431 & 0,642 & 0,834 & 1,000 \\
\hline
\end{tabular}

\begin{tabular}{|l|c|c|c|c|c|}
\cline { 2 - 6 } \multicolumn{1}{c|}{ South and Central Asia } & 1st princ.comp & 2nd princ.comp & 3rd princ.comp & 4th princ.comp & $\begin{array}{c}\text { 5th } \\
\text { princ.comp }\end{array}$ \\
\hline Eigenvalue & 20,7 & 7,3 & 4,0 & 3,5 & 2,5 \\
\hline Cumulative eigenvalue & 20,7 & 28,0 & 32,0 & 35,6 & 38,1 \\
\hline
\end{tabular}




\begin{tabular}{|l|l|l|l|l|l|} 
Variance proportion & 0,470 & 0,167 & 0,091 & 0,080 & 0,058 \\
\hline Cumulative proportion & 0,470 & 0,637 & 0,728 & 0,807 & 0,865 \\
\hline
\end{tabular}

\begin{tabular}{|l|c|c|c|c|c|}
\cline { 2 - 6 } \multicolumn{1}{c|}{ Pacific Asian } & 1st princ.comp & 2nd princ.comp & 3rd princ.comp & 4th princ.comp & $\begin{array}{c}5 \text { th } \\
\text { princ.comp }\end{array}$ \\
\hline Eigenvalue & 15,1 & 2,9 & 2,1 & 1,7 & 1,3 \\
\hline Cumulative eigenvalue & 15,1 & 18,1 & 20,2 & 21,9 & 23,1 \\
\hline Variance proportion & 0,614 & 0,120 & 0,086 & 0,069 & 0,052 \\
\hline Cumulative proportion & 0,614 & 0,734 & 0,819 & 0,889 & 0,940 \\
\hline
\end{tabular}

\begin{tabular}{l}
\cline { 2 - 3 } \multicolumn{1}{l|}{ North America } \\
\begin{tabular}{|l|c|c|}
\hline Eigenvalue & 7,6 & 1,4 \\
\hline Cumulative eigenvalue & 7,6 & 9,0 \\
\hline Variance proportion & 0,840 & 0,160 \\
\hline Cumulative proportion & 0,840 & 1,000 \\
\hline
\end{tabular}
\end{tabular}

\begin{tabular}{|l|c|c|c|c|c|}
\cline { 2 - 6 } \multicolumn{1}{c|}{ South America } & 1st princ.comp & 2nd princ.comp & 3rd princ.comp & 4th princ.comp & $\begin{array}{c}5 \text { th } \\
\text { princ.comp }\end{array}$ \\
\hline Eigenvalue & 20,6 & 3,0 & 2,5 & 2,2 & 1,2 \\
\hline Cumulative eigenvalue & 20,6 & 23,6 & 26,1 & 28,4 & 29,6 \\
\hline Variance proportion & 0,695 & 0,102 & 0,086 & 0,076 & 0,042 \\
\hline Cumulative proportion & 0,695 & 0,796 & 0,882 & 0,958 & 1,000 \\
\hline
\end{tabular}




\begin{tabular}{|c|c|c|c|}
\hline \multicolumn{4}{|c|}{$\begin{array}{l}\text { Table } 6 \\
\text { Coefficients on the AR(1) regression with crisis dummy of the dynamic } \\
\text { correlation coefficient ofthe different regional factor's residuals and the US } \\
\text { residuals as outlined in the equations } 8 \text { \& } 9\end{array}$} \\
\hline \multicolumn{4}{|l|}{${ }^{* * *}$ indicate $1 \%$ significane level. } \\
\hline Regional factor & Y0 & p1 & $\delta$ \\
\hline Western Europé & $0,0523 * * *$ & $0,89 * * *$ & $0,020 * * *$ \\
\hline Eastern Europé & $0,33 * * *$ & $0,39 * * *$ & $0,090 * * *$ \\
\hline Nordic & $-0,022 * * *$ & $0,95 * * *$ & $-0,011 * * *$ \\
\hline MENA & $0,024^{* * *}$ & $0,94^{* * *}$ & $0,0071^{* * *}$ \\
\hline Africa & $0,026 * * *$ & $0,93 * * *$ & $0,010 * * *$ \\
\hline South and Central Asia & $0,010^{* * *}$ & $0,96 * * *$ & $0,0086 * * *$ \\
\hline Pacific Asian & $0,013^{* * *}$ & $0,95 * * *$ & $0,0083 * * *$ \\
\hline North America & $0,14^{* * *}$ & $0,82 * * *$ & $0,0094^{* * *}$ \\
\hline South America & $0,043 * * *$ & $0,93 * * *$ & $0,013 * * *$ \\
\hline
\end{tabular}

Table 7: Granger Causality: Crisis Period ( ${ }^{\text {st }}$ Sept. $2008-31^{\text {st }}$ Dec. 2009)

\begin{tabular}{|c|c|c|c|c|c|}
\hline \multicolumn{2}{|c|}{ West European Countries } & \multicolumn{2}{|c|}{ South and Central Asia } & \multicolumn{2}{|c|}{ MENA } \\
\hline Direction of Causality & Test Statistics & $\begin{array}{l}\text { Direction of } \\
\text { Causality }\end{array}$ & Test Statistics & Direction of Causality & Test Statistics \\
\hline US $\rightarrow$ Austria & $27,5707 * * *$ & US $\rightarrow$ India & $7,26220 * * *$ & US $\rightarrow$ Egypt & $32,4636^{* * *}$ \\
\hline Austria $\rightarrow$ US & 0,97191 & India $\rightarrow$ US & $4,68704 * *$ & Egypt $\rightarrow$ US & $2,64318^{*}$ \\
\hline $\mathrm{US} \rightarrow$ Belgium & $9,10236^{* * *}$ & $\mathrm{US} \rightarrow$ Pakistan & 1,26367 & $\mathrm{US} \rightarrow$ Morocco & $8,28527 * * *$ \\
\hline Belgium $\rightarrow$ US & $4,32366 * *$ & Pakistan $\rightarrow$ US & 1,33818 & Morocco $\rightarrow$ US & 0,30654 \\
\hline US $\rightarrow$ France & $41,9941 * * *$ & $\mathrm{US} \rightarrow$ Sri Lanka & $3,20025 * *$ & US $\rightarrow$ Bahrain & $2,94033^{*}$ \\
\hline France $\rightarrow$ US & $2,82096^{*}$ & Sri Lanka $\rightarrow$ US & $5,63057 * *$ & Bahrain $\rightarrow$ US & $4,06820 * *$ \\
\hline US $\rightarrow$ Germany & $21,9420^{* * *}$ & US $\rightarrow$ Kazakhstan & $43,9322 * * *$ & US $\rightarrow$ Israel & $9,93567 * * *$ \\
\hline Germany $\rightarrow$ US & $3,18402 * *$ & Kazakhastan $\rightarrow$ US & $5,95000 * *$ & Israel $\rightarrow$ US & $4,36229 * *$ \\
\hline US $\rightarrow$ Greece & $20,0726^{* * *}$ & US $\rightarrow$ China & $36,4215 * * *$ & US $\rightarrow$ Jordan & $19,3542 * * *$ \\
\hline Greece $\rightarrow$ US & 1,78820 & China $\rightarrow$ US & $3,32611 * *$ & Jordan $\rightarrow$ US & $3,18590 * *$ \\
\hline US $\rightarrow$ Ireland & $20,6609 * * *$ & US $\rightarrow$ Hong Kong & $39,5398 * * *$ & US $\rightarrow$ Kuwait & $2,92437^{*}$ \\
\hline Ireland $\rightarrow$ US & $3,19686 * *$ & Hong Kong $\rightarrow$ US & $4,4,74799 * *$ & Kuwait $\rightarrow$ US & 0,10408 \\
\hline US $\rightarrow$ Italy & $37,5518^{* * *}$ & US $\rightarrow$ Korea & $31,2284 * * *$ & US $\rightarrow$ Lebanon & $12,3315 * * *$ \\
\hline Italy $\rightarrow$ US & 0,01569 & Korea $\rightarrow$ US & $5,46066 * *$ & Lebanon $\rightarrow$ US & 0,55539 \\
\hline $\mathrm{US} \rightarrow$ Netherlands & $30,3250 * * *$ & $\mathrm{US} \rightarrow$ T aiwan & $38,3099 * * *$ & $\mathrm{US} \rightarrow$ Oman & $28,7711 * * *$ \\
\hline Netherlands $\rightarrow$ US & $2,54464 *$ & Taiwan $\rightarrow$ US & $5,52664 * *$ & Oman $\rightarrow$ US & 0,32140 \\
\hline US $\rightarrow$ Portugal & $32,7039 * * *$ & US $\rightarrow$ Thailand & $15,1923^{* * * *}$ & $\mathrm{US} \rightarrow$ Qatar & $32,6068^{* * *}$ \\
\hline Portugal $\rightarrow$ US & $5,30927 * *$ & Thailand $\rightarrow$ US & $3,20822 * *$ & Qatar $\rightarrow$ US & 0,27508 \\
\hline US $\rightarrow$ Spain & $32,8802 * * *$ & Pacific & Asia & $\mathrm{US} \rightarrow \mathrm{UAE}$ & $21,1070^{* * *}$ \\
\hline Spain $\rightarrow$ US & $3,26182 * *$ & & & $\mathrm{UAE} \rightarrow \mathrm{US}$ & 0,22422 \\
\hline US $\rightarrow$ Switzerland & $40,4614 * * *$ & US $\rightarrow$ Indonesia & $31,9130^{* * *}$ & $\mathrm{US} \rightarrow$ Turkey & $15,3088^{* * *}$ \\
\hline
\end{tabular}




\begin{tabular}{|c|c|c|c|c|c|}
\hline Switzerland $\rightarrow$ US & $2.44439 *$ & Indonesia $\rightarrow$ US & $4,87319 * *$ & Turkey $\rightarrow$ US & $6,01649 * *$ \\
\hline $\mathrm{US} \rightarrow \mathrm{UK}$ & $41,3580^{* * *}$ & US $\rightarrow$ Japan & $106,072 * * *$ & US $\rightarrow$ T unisia & $15,4357 * * *$ \\
\hline $\mathrm{UK} \rightarrow \mathrm{US}$ & 0,49701 & Japan $\rightarrow$ US & 2,02427 & Tunisia $\rightarrow$ US & $5,98147 * *$ \\
\hline \multicolumn{2}{|c|}{ East European Countries } & $\begin{array}{l}\text { US } \rightarrow \text { Australia } \\
\text { Australia } \rightarrow \text { US }\end{array}$ & $\begin{array}{l}119,891 * * * \\
4,39149 * *\end{array}$ & \multicolumn{2}{|l|}{ Nordic Countries } \\
\hline US $\rightarrow$ Croatia & $57,7918 * * *$ & US $\rightarrow$ New Zealand & $112,058 * * *$ & US $\rightarrow$ Denmark & $36,6743 * * *$ \\
\hline Croatia $\rightarrow$ US & 0,35896 & New Zealand $\rightarrow$ US & $5,02185^{*}$ & Denmark $\rightarrow$ US & 0,94602 \\
\hline US $\rightarrow$ Czech Republic & $36,8568 * * *$ & $\mathrm{US} \rightarrow$ Vietnam & $41,3734 * * *$ & US $\rightarrow$ Finland & $28,6825^{* * *}$ \\
\hline Czech Republic $\rightarrow$ US & $3,87875^{* *}$ & Vietnam $\rightarrow$ US & $3,44106 * *$ & Finland $\rightarrow$ US & 0,24410 \\
\hline US $\rightarrow$ Estonia & $38,2933^{* * *}$ & US $\rightarrow$ Malaysia & $32,6825 * * *$ & US $\rightarrow$ Norway & $21,9463 * * *$ \\
\hline Estonia $\rightarrow$ US & 0,53231 & Malaysia $\rightarrow$ US & $3,68654 * *$ & Norway $\rightarrow$ US & 1,44376 \\
\hline $\mathrm{US} \rightarrow$ Hungary & $19,0913 * * *$ & US $\rightarrow$ Philippines & $106,515^{* * *}$ & $\mathrm{US} \rightarrow$ Sweden & 1,95031 \\
\hline Hungary $\rightarrow$ US & $5,75883 * *$ & Philippines $\rightarrow$ US & $5,59731 * *$ & Sweden $\rightarrow$ US & $4,34713 * *$ \\
\hline US $\rightarrow$ Poland & $19,0809 * * *$ & US $\rightarrow$ Singapore & $21,1941 * * *$ & \multirow{2}{*}{\multicolumn{2}{|c|}{ North America }} \\
\hline Poland $\rightarrow$ US & 1,38588 & Singapore $\rightarrow$ US & $5,53825 * *$ & & \\
\hline US $\rightarrow$ Romania & $18,2744 * * *$ & \multirow{2}{*}{\multicolumn{2}{|c|}{ South America }} & US $\rightarrow$ Mexico & $6,97143 * *$ \\
\hline Romania $\rightarrow$ US & 0,48160 & & & Mexico $\rightarrow$ US & $5,46031 * *$ \\
\hline US $\rightarrow$ Russia & $8,38921 * * *$ & US $\rightarrow$ Argentina & $18,1183 * * *$ & US $\rightarrow$ Canada & $13,5651 * * *$ \\
\hline Russia $\rightarrow$ US & $4,34315^{* *}$ & Argentina $\rightarrow$ US & $7,11007 * * *$ & Canada $\rightarrow$ US & $8,96849 * * *$ \\
\hline \multirow{10}{*}{$\begin{array}{l}\text { US } \rightarrow \text { Slovenia } \\
\text { Slovenia } \rightarrow \text { US }\end{array}$} & $77,3146^{* * *}$ & US $\rightarrow$ Brazil & $13,4506^{* * *}$ & \multirow{2}{*}{\multicolumn{2}{|c|}{ Africa }} \\
\hline & 1,17323 & Brazil $\rightarrow$ US & $3,60040 * *$ & & \\
\hline & & US $\rightarrow$ Chile & $11,3786^{* * *}$ & US $\rightarrow$ Kenya & $14,7920 * * *$ \\
\hline & & Chile $\rightarrow$ US & 2,06011 & Kenya $\rightarrow$ US & 1,08993 \\
\hline & & US $\rightarrow$ Colombo & $34,0754 * * *$ & US $\rightarrow$ Mauritius & $21,5109 * * *$ \\
\hline & & Colombo $\rightarrow$ US & $6,55616^{* *}$ & Mauritius $\rightarrow$ US & $3,90209 * *$ \\
\hline & & $\mathrm{US} \rightarrow$ Peru & $8,20561 * * *$ & US $\rightarrow$ Nigeria & 2,13641 \\
\hline & & $\mathrm{Peru} \rightarrow \mathrm{US}$ & $3,72594 * *$ & Nigeria $\rightarrow$ US & 1,97374 \\
\hline & & & & $\mathrm{US} \rightarrow$ South Africa & $44,2931 * * *$ \\
\hline & & & & South Africa $\rightarrow$ US & $4,74506^{* *}$ \\
\hline
\end{tabular}



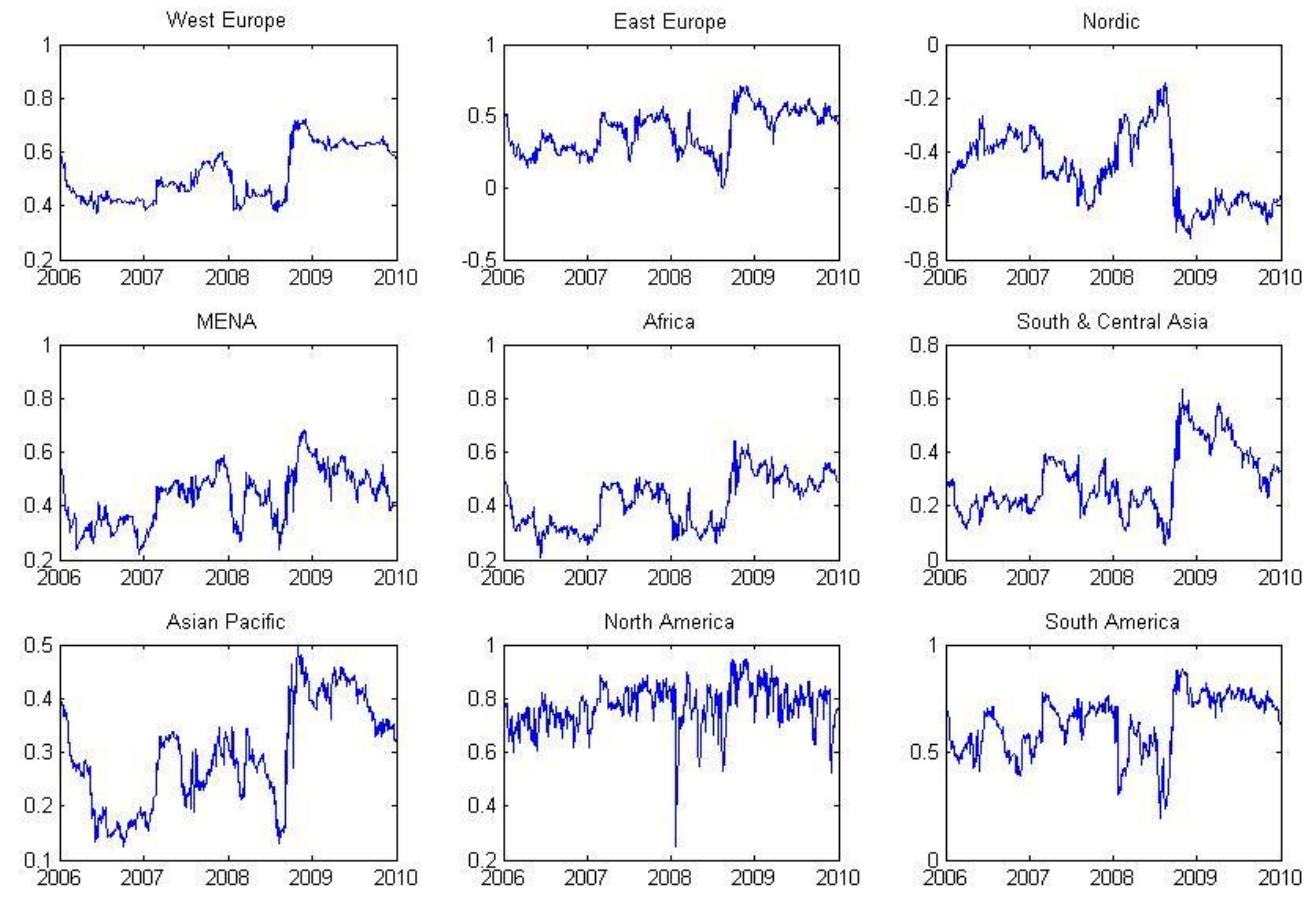

Figure 2 - Subplots of the dynamic correlation between the regional factor residual and the residual of the US index obtained through equation 3 
Figure 3: Response to Cholesky's One standard deviation innovations of US to other countries through impulse response function
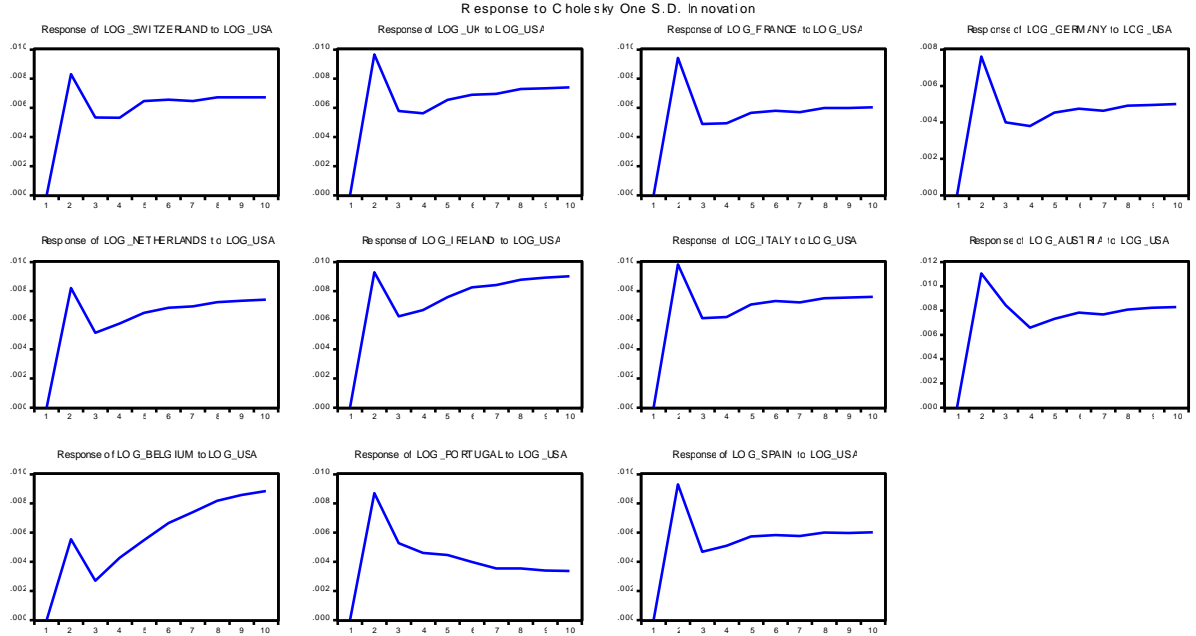

Response to Cholesky One S.D. Innovations (Nordic countries)

Response of LOG_NORWAY to LOG_USA

Response ol LOG SWEDEN to LOG USA
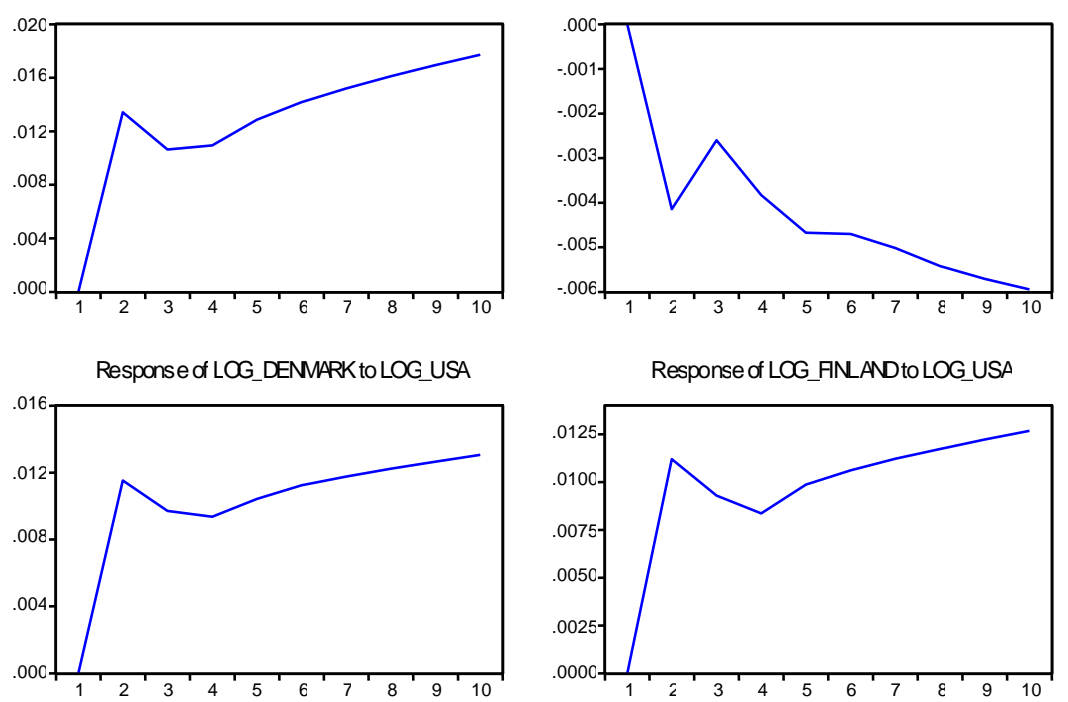

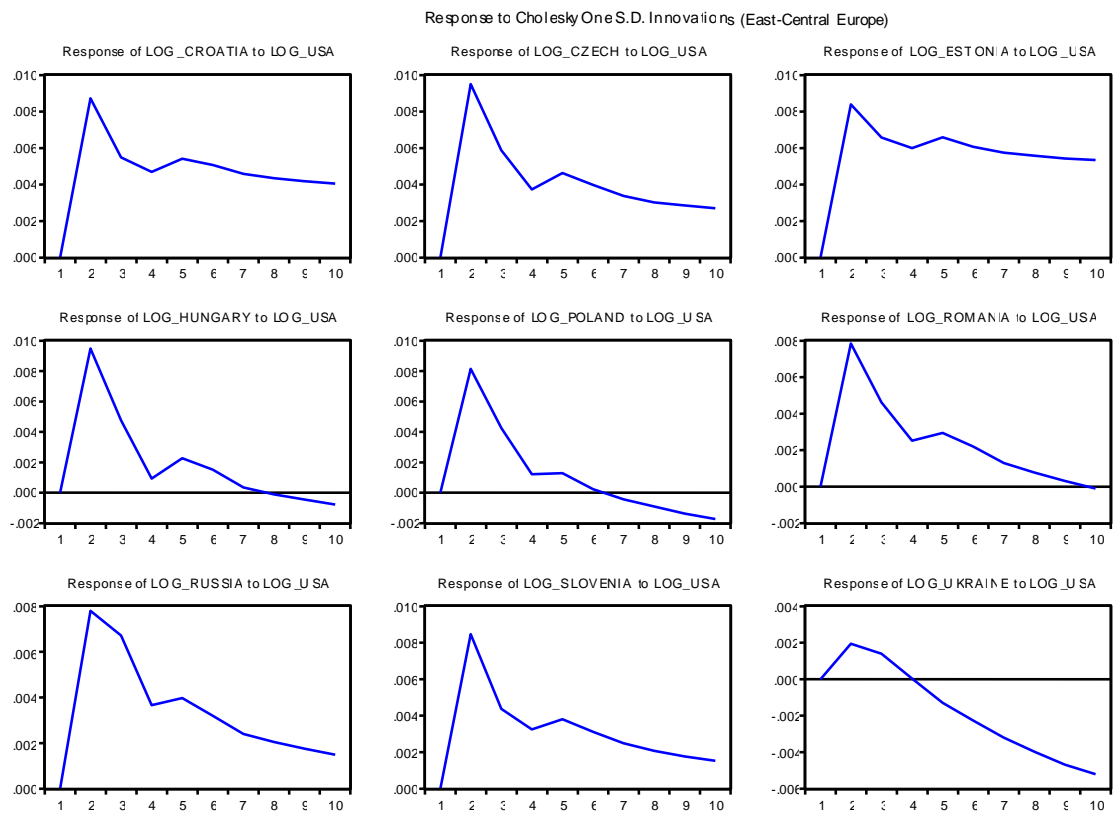

Responseto Cholesky One S.D. Innovations (Africa)

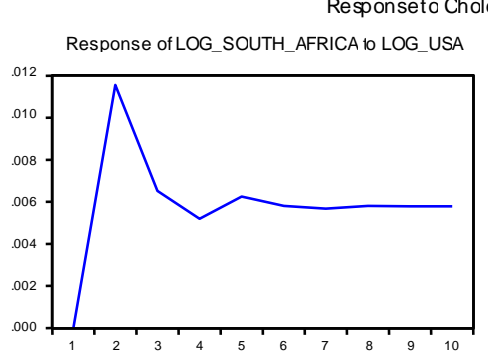

Response of LCG_NIGER IA tc LOG_LSA
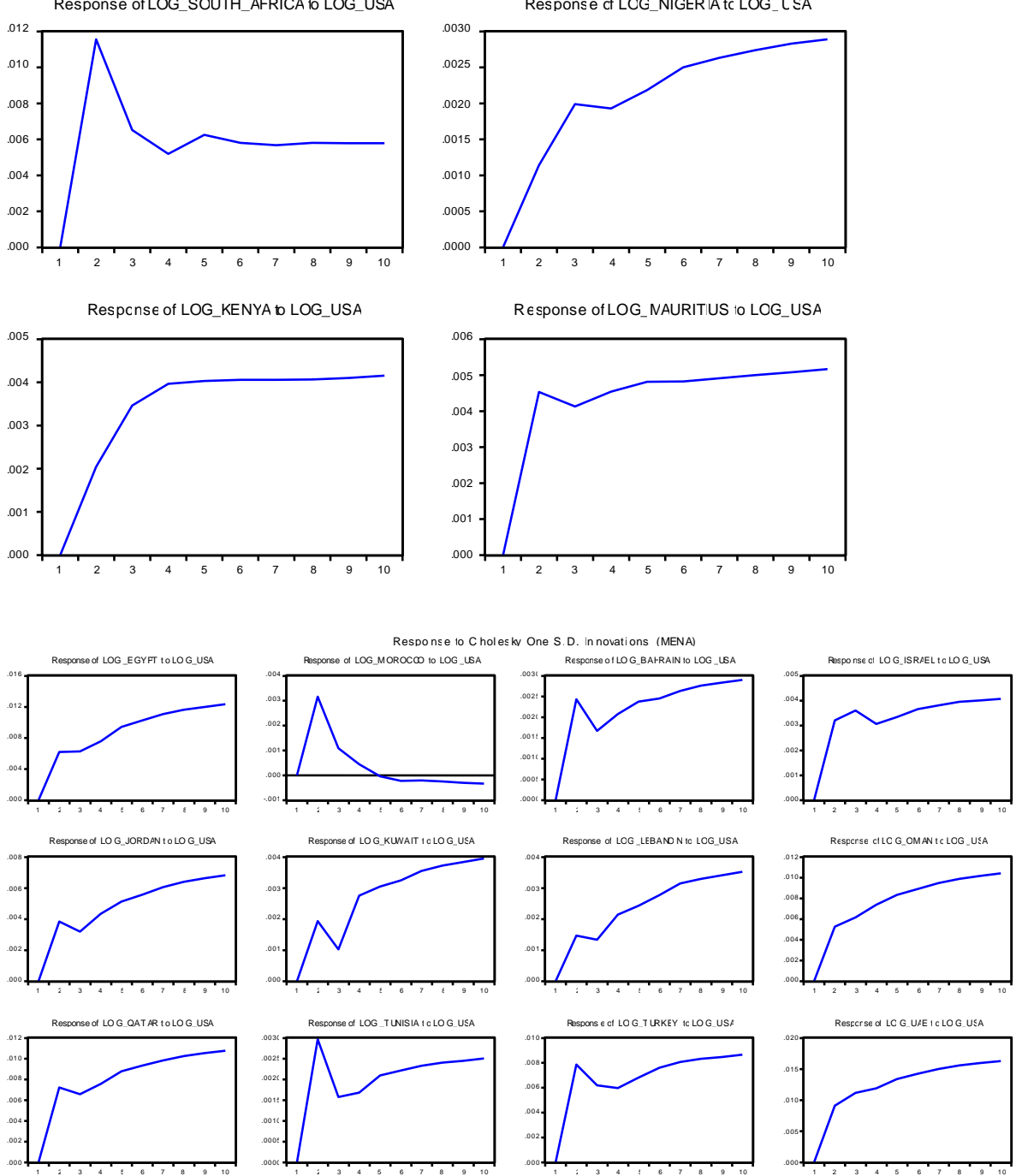


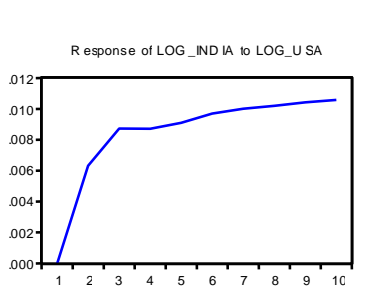

Ke sponse to Cholesty Cne S.U. In novallons (South -Central Asia)

Response of LOG_PAKISTAN to LOG_USA.

Response of LOG_SRI LANKA to LOG_USA
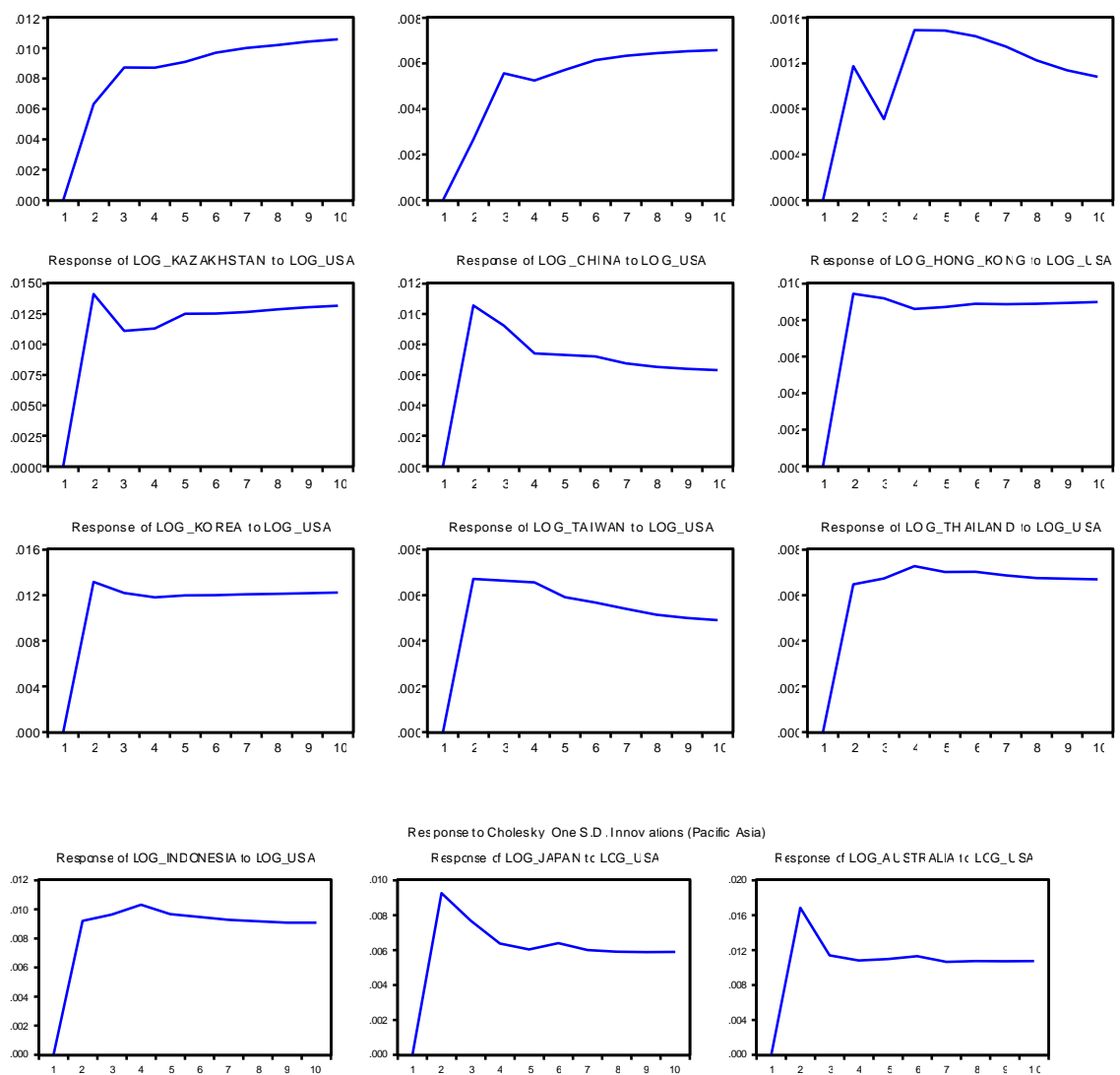

Res ponse to Cholesky One S.D. Innov ations (Pacific Asia)
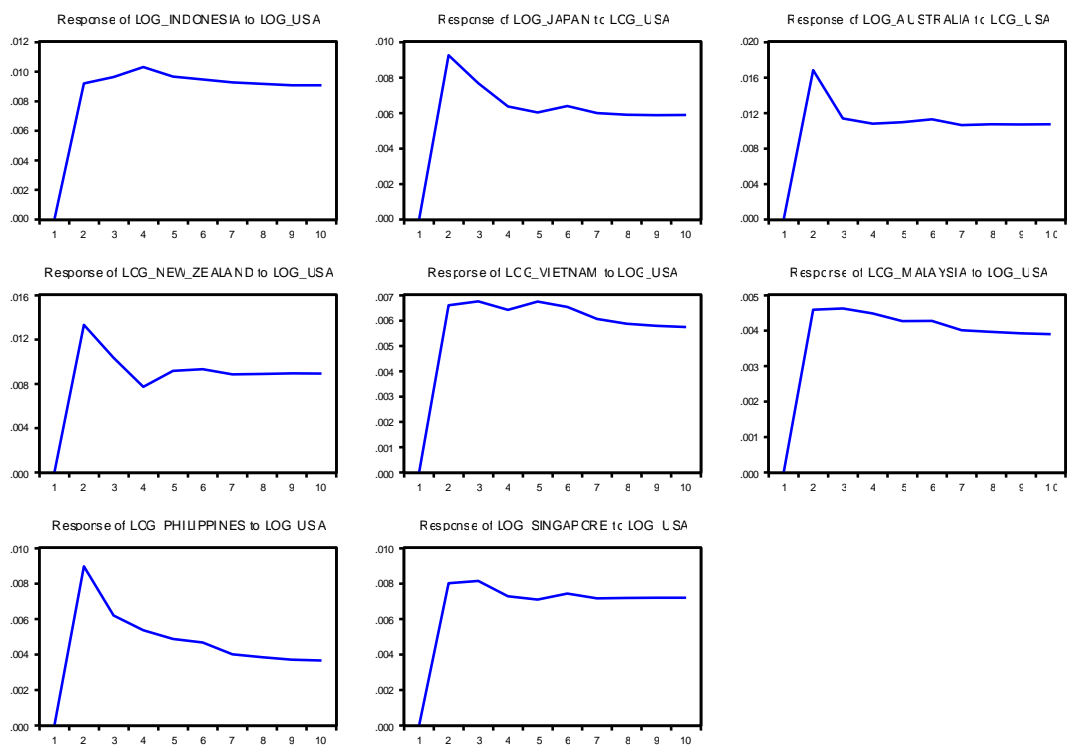
Response to Cholesky One S.D. Innovations (South America)

Respons e o1 LOG_ARGENTINA to LOG_USA

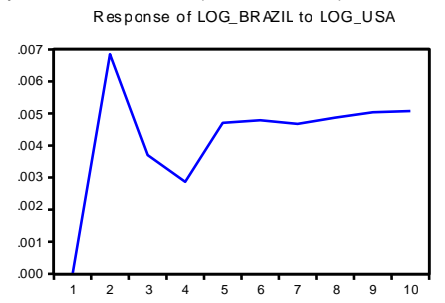

Response of LOG_CHILE to LOG_USA

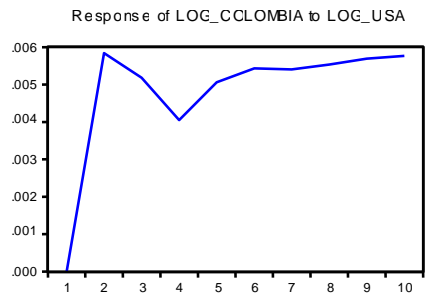

Respons e of LOG_PERU to LOG_USA

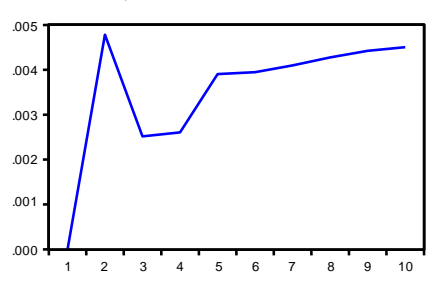

Response to Cholesky OneS.D. Imnovations (North America)

Pesponse of LOG_MEXCOTOLOG LSA

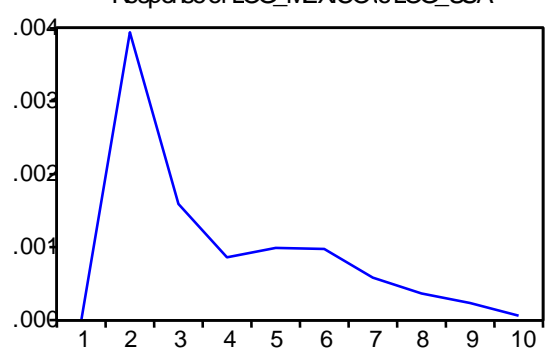

Response of LOG_CANADA toLOG_USA

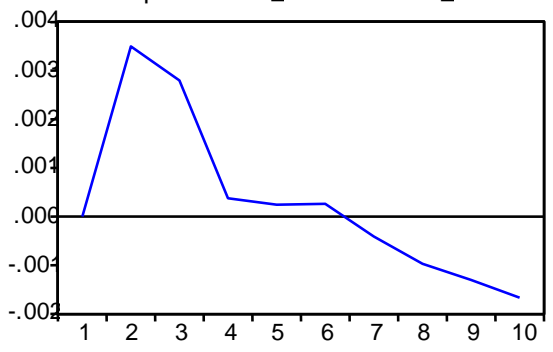




\section{Appendix A1: Johansen and VAR Framework}

We implemented the Vector Autoregressive (VAR) framework for contagion testing for financial markets. Despite the fact that non-stationarity is a common phenomenon among time series data in level terms (Smith, 2001), it is a necessary condition for co-integration test (Lindquist, 2009); therefore, ADF, PP, and KPSS tests for unit root should be implemented in the first place to check the stationarity of the data. The AIC should be used to determine the appropriate lag length for the the unit root tests. While the condition of stationarity is satisfied, we should process the data following these procedure in testing co-integration:

Step 1: The Johansen procedure: Engle and Granger's (1987) two-step method is the commonly recommended procedure for determining the cointegration between $y_{t}$ and $x_{t}$. However, the two-step method goes by an asymmetric fashion where one has to determine if the explanatory variables have endogenous or exogenous characteristics. It is therefore more convenient to use a test where all variables are treated as endogenous and goes by a symmetric fashion (Kleiber and Zeileis, 2008). For that reason, the Johansen procedure is conducted, which have its roots in the Johansen's full-information maximum likelihood approach that determines if there is a long run cointegration between the selected variables (Kleiber and Zeileis, 2008). It goes by a Vector autoregressive (VAR) representation with pth order (p) as shown by Kleiber and Zeileis (2008) and Pfaff (2008) as:

$$
\begin{aligned}
& \Delta y_{t}=\Pi y_{t-1}+\sum_{j=1}^{p-1} \Gamma_{\mathrm{j}} \Delta y_{t-j}+D_{t}+\varepsilon_{t} \\
& r k(\Pi)=\mathrm{K} \\
& r k(\Pi)=0 \\
& 0<r k(\Pi)=\mathrm{r}<K
\end{aligned}
$$

where $K$ represents the rank of the matrix $\Pi$. Equation (10) tells us that the variables testes are stationary and $\Pi$ is a full rank. Equation (11) tells us that $\Pi$ is zero and no cointegration exists. Equation (12) however, tells us that the rank of $\Pi$ is neither a full rank nor equal to zero, which means that there is a cointegration between the variables. The Johansen procedure can be specified to measure long run effects and transitory effects. The difference lays in the $\Gamma_{\mathrm{j}}$ matrix specification where $\Gamma_{\mathrm{j}}=-\left(\Pi_{\mathrm{j}+1}+\cdots+\Pi_{\mathrm{k}}\right)$, measures the transitory effects and $\Gamma_{\mathrm{j}}=-\left(\mathrm{I}_{\mathrm{k}}-\Pi_{1}-\cdots-\Pi_{\mathrm{k}}\right)$, the long run effects for $\mathrm{j}=1, \ldots, \mathrm{k}-1$ (see. e.g. Pfaff, 2008). The Johansen procedure is also based on two test statistics, the maximum Eigenvalue and the trace statistic. Pfaff (2008) shows that the trace statistic: $J_{\text {Trace }}=-T \sum_{i=r+1}^{n} \ln \left(1-\hat{\lambda}_{i}\right)$ has 
the null hypothesis of cointegrating vectors being $r$ at the most while the eigenvalue statistic: $J_{\text {Eigen }}(r, r+1)=-T \ln \left(1-\hat{\lambda}_{r+1}\right)$ goes by a null hypothesis of cointegrating vectors being $r$. As argued by Nourzad and Grennier (1995), the difference between the trace and eigenvalue test lays in their hypothesis. The critical values for the Trace and Maximum Eigenvalue statistic are to be found in Osterwald-Lenum (1992) and Doornik (1998).

Step 2: VAR Framework: Depending on the outcome of the cointegration tests, a vector autoregressive or a vector error correction approach will be used in order to conduct this research. If there is a cointegration between the series, the VAR model has to be transformed into a VECM, which is a restricted VAR created to deal with non-stationary variables. Engle and Granger (1987) noticed that when modeling with VARs where the variables are cointegrated, their estimates in first differences or levels will be biased and; therefore, suggests the VECM (Penm et al., 1997). As shown by Lutkepohl (2004) the model specification is in line with Johansen (1991) and presented as:

$$
\begin{gathered}
{\left[\begin{array}{l}
x_{t} \\
y_{t}
\end{array}\right]=\alpha \beta^{\prime}\left[\begin{array}{l}
x_{t-1} \\
y_{t-1}
\end{array}\right]+\sum_{i=1}^{p-1}\left[\begin{array}{ll}
\gamma_{11, i} & \gamma_{12, i} \\
\gamma_{21, i} & \gamma_{22, i}
\end{array}\right]\left[\begin{array}{l}
\Delta x_{t-1} \\
\Delta y_{t-1}
\end{array}\right]+\varepsilon_{t}} \\
\gamma_{12, i}=0 \quad i=1, \ldots, p-1 .
\end{gathered}
$$

where:

$\Pi$ represents the product of the $\alpha$ and $\beta$ matrix with the dimensions $(K * r)$ and where $K$ is the set of variables and $r$ the number of cointegrating relationships such that $\Pi=\alpha \beta^{\prime}$. $\Pi$ is often referred to as the long run parameter and $\Gamma$ the short run parameter which captures the long in the former and short run dynamics in the latter of the variables (Lutkepohl, 2004). When there is one cointegrating relationship, $\Pi=\alpha \beta^{\prime}$ can be written as:

$\Pi=\alpha \beta^{\prime}=\left(\begin{array}{l}\alpha_{11} \\ \alpha_{12}\end{array}\right)\left(\begin{array}{ll}\beta_{11} & \beta_{12}\end{array}\right) \ldots(\mathrm{A} 6)$ 
Step 3: Granger-Causality Test: The causality term was introduced by Granger (1969). When lagged values of a variable $\boldsymbol{y}_{\boldsymbol{t}}$ contributes to an improvement of the forecast of a variable $\boldsymbol{x}_{\boldsymbol{t}}$ after being controlled for lagged values of $\boldsymbol{x}_{\boldsymbol{t}}$, it is said to be casual (Wooldridge, 2005 and Lutkepohl, 2004). That is, $\boldsymbol{y}_{\boldsymbol{t}}$ granger causes $\boldsymbol{x}_{\boldsymbol{t}}$ if $\boldsymbol{y}_{\boldsymbol{t}}$ is a useful predictor of $\boldsymbol{x}_{\boldsymbol{t}}$ (Stock and Watson, 2006).As shown by Lutkepohl (2004) and Wooldridge (2005), $\boldsymbol{y}_{\boldsymbol{t}}$ does granger cause $\boldsymbol{x}_{\boldsymbol{t}}$ if and only if:

$E\left(y_{t} \mid I_{t-1}\right) \neq E\left(y_{t} \mid J_{t-1}\right) \ldots(\mathrm{A} 7)$

where:

$I_{t-1}$ contains lagged values on $y$ and $x$, and $J_{t-1}$ only contains lagged values on $y$ generated by a $\operatorname{VAR}(\mathrm{p})$ procss:

$$
\begin{gathered}
{\left[\begin{array}{l}
x_{t} \\
y_{t}
\end{array}\right]=\sum_{i=1}^{p}\left[\begin{array}{ll}
\alpha_{11, i} & \alpha_{12, i} \\
\alpha_{21, i} & \alpha_{22, i}
\end{array}\right]\left[\begin{array}{l}
x_{t-1} \\
y_{t-1}
\end{array}\right]+\varepsilon_{t},} \\
\alpha_{12, i}=0 \quad i=1,2, \ldots, p .
\end{gathered}
$$

and in case of a VECM approach :

$$
\begin{gathered}
{\left[\begin{array}{l}
x_{t} \\
y_{t}
\end{array}\right]=\alpha \beta^{\prime}\left[\begin{array}{l}
x_{t-1} \\
y_{t-1}
\end{array}\right]+\sum_{i=1}^{p-1}\left[\begin{array}{ll}
\gamma_{11, i} & \gamma_{12, i} \\
\gamma_{21, i} & \gamma_{22, i}
\end{array}\right]\left[\begin{array}{l}
\Delta x_{t-1} \\
\Delta y_{t-1}
\end{array}\right]+\varepsilon_{t}} \\
\gamma_{12, i}=0 \quad i=1, \ldots, p-1 .
\end{gathered}
$$

The granger causality test has the ability of predicting each one of our variables statistical impact on their future value (Brooks, 2008), that is, telling us if one variable Granger-causes the other. However, Brooks (2008) argues that the information of a positive or negative relation or the time horizon of when the impact will take place cannot be predicted by a Granger-causality test but Impulse responses on the other hand, have the ability of doing so. Therefore, the Impulse response function is applied. Impulse responses traces the reactions of the dependent variable to a unit shock of all the other variables in a dynamic system, that is, by hitting the error term with a shock, one traces the effects on the dependant variable over time (Brooks 2008). This is showed graphically and has the following representation as in (Lutkepohl, 2004):

$y_{t}=\phi_{0} u_{t}+\phi_{1} u_{t-1}+\phi_{2} u_{t-2}+\cdots$

where,

$\phi_{0}$ is the identity matrix $I_{k}=\left[\begin{array}{ll}\alpha_{1} & \alpha_{2} \\ \beta_{1} & \beta_{2}\end{array}\right]$ and $\phi_{s}=\sum_{j=1}^{s} \phi_{s-j} \mathrm{~A}_{\mathrm{j},} \quad \mathrm{s}=1,2, \ldots$

with $\phi_{0}=I_{k}$ and $\mathrm{A}_{\mathrm{j}}=0$ for $j>p$. 


\section{Appendix A2: Principal Component Analysis}

Principal Component Analysis (PCA) attempts to find the common factors in a given dataset. ${ }^{1}$ More vividly, principal component analysis attempts to find the common dimensions (perspectives) of a multidimensional dataset, where each variable (index in our case) corresponds to a provisory dimension.

Yiu et al (2010) use their Asian factor 'the eigenvector' that corresponds to the largest eigenvalue of their 11 stock markets sample. In similar fashion, we have proposed to use the largest eigenvector(s) of the regional sample (in each region excluding the regional leading country from the sample) as our regional component. The criterion that they have used is the eigenvectors that contributes the most to the selection of the variance proportion. In their case, only the first eigenvector contributes largely to the explained variance proportion, while the rest perform much worse. We have applied the same procedure as of Jolliffe (2002). We have excluded the regional leading market from the sample of region's indices on which PCA is performed, as we have used the regional leading market in our VAR model (eq.3).

After obtaining the regional factors, we have again performed the DCC methodology outlined above in order to test for the presence of contagion between the US and different regions, which are represented by the regional factor(s).

The explanation and derivation of principal component analysis given here is base on Shlens (2005). If we have a matrix of data $\mathbf{X}$ (an mxt matrix where $m$ is the number of indices in our case, and $t$ is the number of observations - returns - for each index), we need then to find a matrix $\mathbf{P}$ such that

$$
Y=P X
$$

and

$$
C_{Y} \equiv \frac{1}{n-1} Y Y^{T}
$$

In such a way that $C_{Y}$ is diagonalised. This results in rows of $\mathbf{P}$ being the principal components of $\mathbf{X}$. Using A1 we can rewrite the equation A2 in the following way

$$
\begin{aligned}
& C_{Y}=\frac{1}{n-1} Y Y^{T} \\
& C_{Y}=\frac{1}{n-1}(P X)(P X)^{T}
\end{aligned}
$$

\footnotetext{
1 "The goal of principal component analy sis is to compute the most meaningful basis to re-express a noisy data set. The hope is that this new basis will filter out the noise and reveal hidden structure. ... Determining this fact allows an experimenter to discern which dynamics are important, which are just redundant and which are just noise.” (Shlens, 2005, p.2)
} 


$$
\begin{aligned}
& C_{Y}=\frac{1}{n-1} P X X^{T} P^{T} \\
& C_{Y}=\frac{1}{n-1} P\left(X X^{T}\right) P^{T} \\
& C_{Y}=\frac{1}{n-1} P A P^{T}
\end{aligned}
$$

Where $A \equiv X X^{T}$ and $\mathbf{A}$ is symmetric. As Shelns (2005) writes a symmetric matrix (A) is diagonalised by an orthogonal matrix of its eigenvectors. This further gives

$$
A=E D E^{T}
$$

Where $\mathbf{D}$ is a diagonal matrix and $\mathbf{E}$ is a matrix of eigenvectors of $\mathbf{A}$ arranged as columns. Further we have that $P \equiv E^{T}$ and $P^{-1}=P^{T}$ we finally obtain that

$$
C_{Y}=\frac{1}{n-1} D
$$

This shows that $C_{Y}$ is diagonal as intended. Our interest lies in the matrix $\mathbf{P}$ (or $\mathbf{E}$ for that matter).

\footnotetext{
${ }^{\text {i }}$ Stockholm University, School of Business, SE-106 91, Stockholm, Sweden. Tel: +468163034, Fax: +4686747440, e-mail: sabur.mollah@fek.su.se (Corresponding Author)

${ }^{i i}$ Stockholm University, School of Business, SE-106 91, Stockholm. Sweden. E-mail: gz@fek.su.se

${ }^{\text {iii }}$ Swedish Agency for Growth Policy Analysis, Studentplan 3, SE- 83140 Östersund, Sweden. E-mail:

Shahid.Quoreshi@tillvaxtanalys.se

${ }^{\text {iv }}$ A detailed overview of the events of the global financial crisis is given in Acharya et al. (2009).

${ }^{v}$ In November, at its minimum value, the index lost $35 \%$ of its value since September 1, 2008.

${ }^{v i}$ Masson (1998 and 1999), Masson and Mussa (1995), Calvo and Reinhart (1996), Forbes and Rigobon (2002),

Pesaran and Pick (2003), Pritsker (2001), Pericoli and Sbracia (2001) and Corsetti et al. (2003).

${ }^{v i i}$ Dynamic conditional correlation (DCC) is tested against the constant conditional correlation (CCC) by implementing Engle and Sheppard (2001) model.

${ }^{\text {viii }}$ We adopted ADCC but the results did not improve; therefore, we did not pursue it any further.

${ }^{i x}$ The models are described in detail in the appendix. However, the appendix section is excluded from the paper because the paper is already too long.

${ }^{\mathrm{x}}$ Weekly data were tested to check robustness. We found no better results using the weekly dataset.

${ }^{x i}$ A landmark institute, Lehman Brothers, collapsed in early September 2008.

${ }^{x i i}$ We conducted the Chow test to check structural breaks for the sample countries. The F-statistics for most of the countries are rejected at the 1\% level for September 2008, which helped us determine September 2008 as the beginning of the global financial crisis.

xiii There can also be different interpretations of the actual start of the crisis. Yiu et al. (2002) take the crash of the sub-prime mortgage market in the U.S. as the start of the crisis. Thus, in their study, the start of the cris is is marked in September 2007. However, we noticed that the market indices declined significantly in September 2008. Thus, we consider September 1, 2008 as the start date of the crisis. The Chow test results also support the notion that the crisis begins in September 2008.

${ }^{\text {xiv }}$ We ran the models with the regional leading country's lag alongside the U.S., but none of the regional leaders was significant. We tested the regional leaders alongside the U.S. to see if the market contagion spread from the regional leader.

${ }^{\mathrm{xv}}$ Given space limitations, we did not produce the results for regional models.
} 
${ }^{x v i}$ The results are not reported given space limitations but are available on request.

xvii We have conducted a co-integration analysis between nine regional countries by implementing the Johansen procedure. Based on the maximu m eigenvalue and the trace statistic, we concluded that all regional countries are integrated at least at level 1 . Given space limitations, we are unable to provide the detailed results, which are available on request.

${ }^{\text {xviii }}$ Sweden implemented a similar resolution method when it tackled the Swedish banking crisis during the 1990s. We believe that the Swedish resolution help it escape the global crisis. 